\title{
Prediction of Gas Injection Effect on Asphaltene Precipitation Onset Using the Cubic and Cubic-Plus-Association Equations of State
}

\author{
Arya, Alay; Liang, Xiaodong; von Solms, Nicolas; Kontogeorgis, Georgios
}

Published in:

Energy and Fuels

Link to article, DOI:

10.1021/acs.energyfuels.6b03328

Publication date:

2017

Document Version

Peer reviewed version

Link back to DTU Orbit

Citation (APA):

Arya, A., Liang, X., von Solms, N., \& Kontogeorgis, G. (2017). Prediction of Gas Injection Effect on Asphaltene Precipitation Onset Using the Cubic and Cubic-Plus-Association Equations of State. Energy and Fuels, 31(3), 3313-3328. https://doi.org/10.1021/acs.energyfuels.6b03328

\section{General rights}

Copyright and moral rights for the publications made accessible in the public portal are retained by the authors and/or other copyright owners and it is a condition of accessing publications that users recognise and abide by the legal requirements associated with these rights.

- Users may download and print one copy of any publication from the public portal for the purpose of private study or research.

- You may not further distribute the material or use it for any profit-making activity or commercial gain

- You may freely distribute the URL identifying the publication in the public portal 


\title{
Prediction of Gas Injection Effect on Asphaltene Precipitation Onset using the Cubic and Cubic-Plus-Association Equations of State
}

\author{
Alay Arya, Xiaodong Liang, Nicolas von Solms, Georgios M. Kontogeorgis* \\ Center for Energy Resources Engineering (CERE), Department of Chemical and Biochemical \\ Engineering, Technical University of Denmark, DK-2800 Kgs. Lyngby, Denmark \\ *To whom correspondence should be addressed. Tel: 45-45252859. Fax: 45-45882258. Email: gk@kt.dtu.dk.
}

\begin{abstract}
Gas injection is a proven enhanced oil recovery technique. The gas injection changes the reservoir oil composition, temperature and pressure conditions, which may result in asphaltene precipitation. In this work, we have used a modeling approach from the literature in order to predict asphaltene precipitation onset condition during gas injection. The modeling approach is used with the Soave-Redlich-Kwong (SRK), Soave-Redlich-Kwong-Plus-HuronVidal mixing rule (SRK+HV) and Cubic-Plus-Association (CPA) equations of state (EoS). Six different reservoir fluids are studied with respect to asphaltene onset precipitation during nitrogen, hydrocarbon gas mixture and carbon dioxide injection. It is also shown how to extend the modeling approach when the reservoir fluid is split into multiple pseudocomponents. It is observed that the modeling approach using any of the three models can predict the gas injection effect on asphaltene onset conditions. The CPA EoS is more reliable than the other two models, which are sensitive to asphaltene molecular weight and sometimes predict highly non-linear behavior outside the experimental temperature range used for fitting the model parameters.
\end{abstract}

\section{Introduction}

Asphaltenes are the solubility fraction of oil, which are insoluble in $n$-heptane and soluble in aromatic solvents such as toluene [1-3]. They form the heaviest, highly polarizable and polydisperse fraction of oil. Their actual chemical structures are very difficult to identify due to their extremely low volatility, the complex and continuous variation in their chemical structures and self-aggregation [4]. Their mass fraction in oil at ambient conditions is generally measured using the Saturates-Aromatics-Resins-Asphaltenes (SARA) analysis. They may precipitate out of oil depending upon the oil temperature, pressure and composition. Thus, they generally create flow assurance problems in the oil industry by reducing the permeability of reservoirs, forming scale, and plugging the wellbore. The asphaltene flow assurance problem is analyzed by Pressure-Temperature (PT) plots as shown in Fig. 6. There are two 
PT boundaries, the upper onset pressure (UOP) boundary, above which only one (liquid) phase exists, and the lower onset pressure (LOP) boundary, above which three phases (gas, asphaltene-lean liquid, and asphaltene-rich liquid) exist. Asphaltene precipitation occurs between these two boundaries. Maximum asphaltene precipitation occurs at bubble pressure.

Generally, gas is injected into the reservoir, after water flooding, in order to maintain its pressure and recover more oil. Miscible flooding with carbon dioxide $\left(\mathrm{CO}_{2}\right)$ or hydrocarbon $(\mathrm{H} / \mathrm{C})$ solvents is considered one of the most effective enhanced oil recovery processes applicable to light and medium oil reservoirs [5]. Miscible $\mathrm{CO}_{2}$ displacement results in approximately $22 \%$ additional recovery, while immiscible displacement achieves approximately $10 \%$ additional recovery [6]. In addition, $\mathrm{CO}_{2}$ has a considerably lower minimum miscibility pressure (MMP) compared to nitrogen $\left(\mathrm{N}_{2}\right)$ and methane $[7,8]$. The MMP is the minimum pressure at which around $95 \%$ of contacted oil is recovered for a given temperature. The MMP depends upon the reservoir temperature and oil composition $[8,9]$. With new technology in horizontal drilling and stimulation, the oil production from tight reservoirs is increasing. Although the initial production rates are high, the recovery factors are low (around 5-10\%). Water flooding is not a feasible option for these tight reservoirs due to low permeability; however, gas injection may be a good alternative option based on recent analysis [10]. The asphaltene solubility in oil usually decreases with the amount of injected gas, which increases the upper onset pressure for a given temperature. Therefore, there is a need to develop a model to predict asphaltene onset conditions during gas injection.

There are different models in the literature to study asphaltene precipitation but only a few researchers have studied the effect of gas injection into reservoir fluid using cubic equations of state (EoS). EoS based compositional reservoir simulations use almost exclusively cubic EoS such as the Soave-Redlich-Kwong (SRK) and Peng-Robinson (PR) equations [11]. A logical option is therefore to develop a modeling approach based on these EoS to predict the gas injection effect on asphaltene onset conditions. Jamaluddin et al [12] studied the SRK EoS to describe two reservoir fluids. They could correlate the asphaltene UOP boundary by tuning the model parameters and predict the lower onset pressure boundary. Pedersen et al [13] studied both SRK and PR EoS and could also correlate the UOP boundary and predict the lower onset pressure boundary. Panuganti et al [14] studied the SRK and PerturbedChain-Statistical-Associating-Fluid-Theory (PC-SAFT) EoS for one reservoir fluid and concluded that the SRK EoS was not able to predict the hydrocarbon gas injection effect on the UOP boundary with the same set of binary interaction parameters. They did not study the SRK EoS for $\mathrm{CO}_{2}$ and $\mathrm{N}_{2}$ injections. On the other hand, Hustad et al [15] also used SRK and PC-SAFT for one reservoir fluid and concluded that both models performed well in predicting the asphaltene UOP during $\mathrm{N}_{2}$ injection at constant temperature. There was no discussion about how their model would work at different temperatures. Zhang et al [16] and Arya et al 
[17-19] studied the CPA EoS using different modeling approaches and concluded that the CPA EoS can predict the gas injection effect. Given the mixed results of these studies for modeling asphaltene precipitation during gas injection using cubic EoS, more investigations are needed.

In this work, we study the CPA, SRK and SRK+HV models with respect to asphaltene precipitation onset condition during gas injection. The Huron-Vidal mixing rule can fit the excess Gibbs energy data (over wide pressure range) better than the classical mixing rule for the binary mixture containing asymmetric molecules. The sole purpose of using the SRK $+\mathrm{HV}$ model is to analyze whether it (SRK+HV) can impart any improvements over the SRK (with classical mixing rule) model. To the best of our knowledge, the SRK+HV model has never been used before for such studies. We first describe the modeling approach and parameters used for all three models. Then we study six different reservoir fluids to check the reliability of the models for the prediction of the gas injection effect. We also study how to extend the modeling approach when the plus fraction (e.g. hexane plus fraction) needs to be split into multiple pseudo-components in order to predict PVT properties.

\section{Modeling Approach}

In this work we take the same modeling approach as presented by Arya et al [17-19] and shown in Fig. 1. The reservoir fluid is divided into defined components (shown in Table 5) and $C_{6+}$ fraction. The $C_{6+}$ fraction is further divided into heavy component $(\mathrm{HC})$ and asphaltene. The heavy component can be also divided into multiple components: this approach is studied and discussed in the Results \& Discussion section. Once the temperature dependent nonideality between the heavy component and asphaltene pair is appropriately modeled, the gas injection effect can be predicted. The literature shows that the asphaltene solubility parameter varies from 19 to $23 \mathrm{MPa}^{1 / 2}$ depending upon the source [2,22]. The asphaltene component critical temperature, pressure and acentric factor are fixed based on our experience [19], which result its solubility parameter of $19 \mathrm{MPa}^{1 / 2}$ at $298 \mathrm{~K}$ and $1 \mathrm{~atm}$. The asphaltene rich phase is modeled as a liquid phase [23]. The normal boiling point of the heavy component is calculated from the Pedersen relationship [13]. The heavy component critical temperature $\left(T_{c}\right)$, pressure $\left(P_{c}\right)$ and acentric factor $(\omega)$ are calculated from the Kesler-Lee correlation [24] using the information of molecular weight (MW) and specific gravity (SG) of stock tank oil (STO). The critical pressure $\left(P_{c}\right)$ of the heavy component is then tuned with respect to experimental data of bubble point of the reservoir fluid. As shown in Fig. 2, overall reservoir fluid is divided into three groups. Group-1 consists of gas components and alkanes lighter than $C_{6+}$ fraction. Groups-2 and 3 consist of heavy component and asphaltene respectively. The binary interaction parameters for gas/alkane-heavy component $\left(k_{12}\right)$ pairs are fixed and 
obtained from the literature $[15,28]$. For binary pairs of heavy component with $\mathrm{N}_{2}$ and $\mathrm{CO}_{2}$, the heavy component is assumed as the lumped fraction of single carbon number components ranging from 50 to 80 [15]. For binary pair of heavy component with $\mathrm{H}_{2} \mathrm{~S}$, the heavy component is assumed as the component with single carbon number of 6 [28]. The binary parameters for gas/alkane-asphaltene pairs, $k_{13}$ in case of the CPA and SRK models and $G_{13} \& G_{31}$ in case of the SRK+HV model, are fitted in this work and more details are given in Results and Discussion section. It should be noted that for the SRK+HV model, the HuronVidal parameters $\left(G_{12}, G_{21}\right)$ for gas $/ n$-alkane-heavy component binaries are calculated from $k_{12}$ to reduce the Huron-Vidal mixing rule to van der Waal's one fluid (classical) mixing rule for those binaries. It is assumed that if the heavy component is divided into multiple components, they each have the same values of $k_{12}, k_{13}$ and Huron-Vidal parameters $\left(G_{12}, G_{21}, G_{13}\right.$ and $G_{31}$ for the SRK+HV model) to simplify the modeling approach.

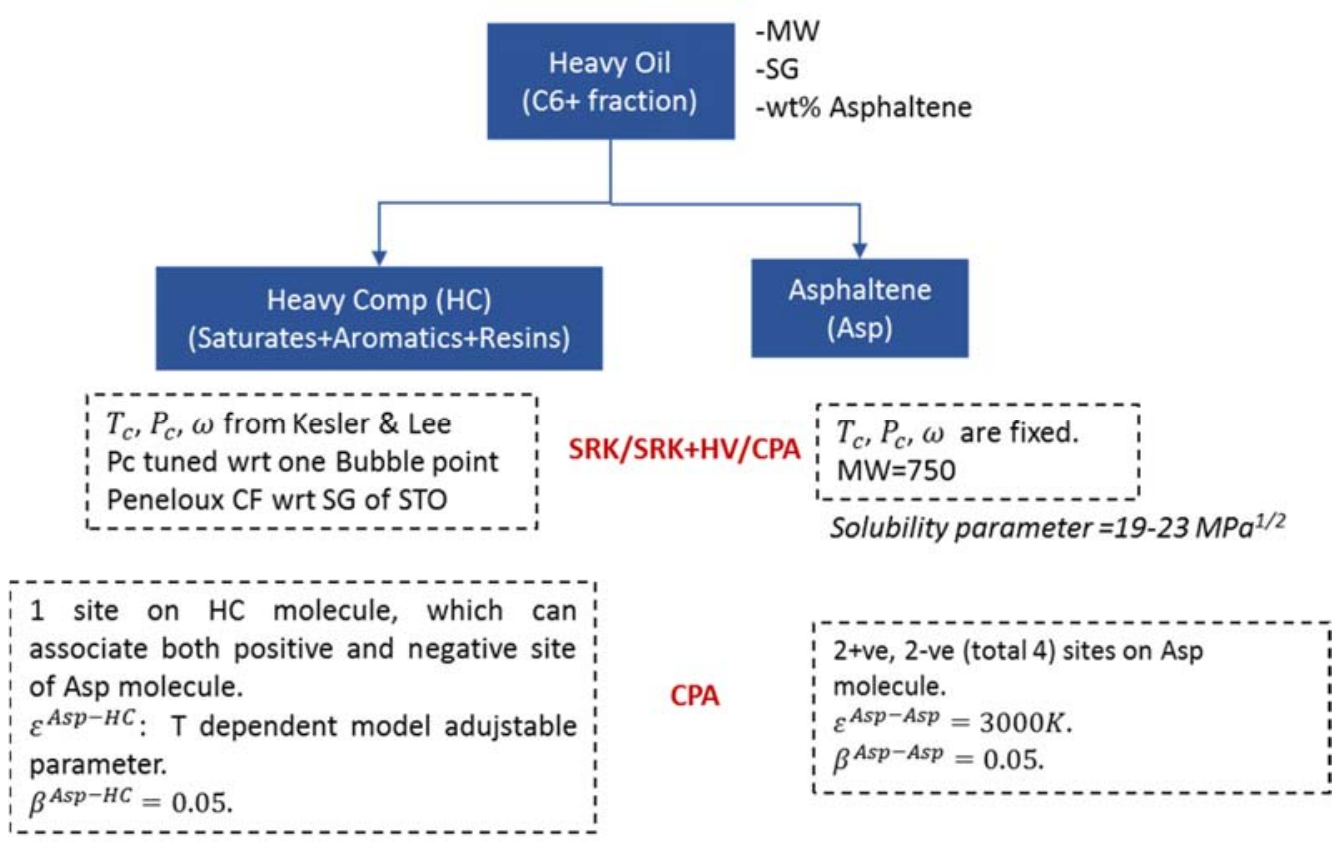

Fig. 1. Characterization procedure of heavy oil/ $C_{6+}$ fraction into two pseudo-components (heavy component $(\mathrm{HC})$ and asphaltene (Asp)). 


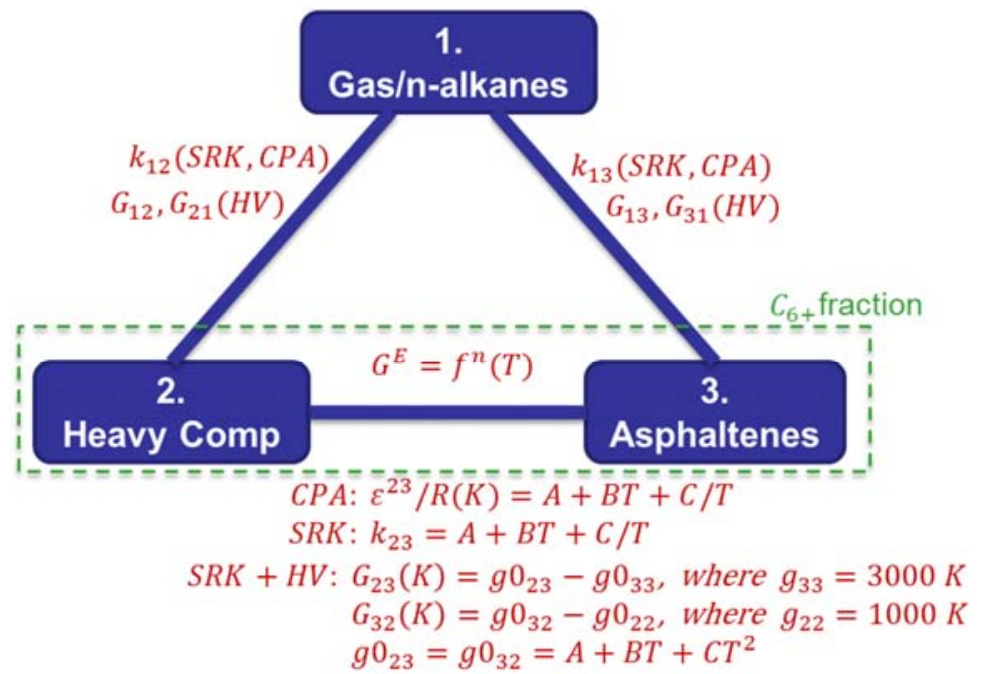

Fig. 2. Modeling approach used in this work for the CPA, SRK and SRK-HV equations of state.

The CPA EoS is described by Kontogeorgis and Folas [25]. For the CPA model, the asphaltene fraction is considered as a monodisperse and associating component. The values of $T_{c}, P_{c}$, and $\omega$ are kept the same as considered in case of the SRK model. The selfassociating energy $\left(\varepsilon^{33} / R\right)$ and volume $\left(\beta^{33}\right)$ between asphaltene molecules are fixed to 3000 $\mathrm{K}$ and 0.05 (dimensionless) respectively. Due to the association, the solubility parameter of asphaltene is increased to $21.51 \mathrm{MPa}^{1 / 2}$ in case of the CPA model from $19 \mathrm{MPa}^{1 / 2}$ in case of the SRK model at $298 \mathrm{~K}$ and $1 \mathrm{~atm}$. One can also use the asphaltene solubility parameter of $19 \mathrm{MPa}^{1 / 2}$ for the CPA model or $21.51 \mathrm{MPa}^{1 / 2}$ for the SRK model, which will necessitate to use a different set of optimized binary interaction parameters $\left(k_{13}\right)$ for gas/alkane-asphaltene pairs. The conclusion of this study will remain the same if the asphaltene solubility parameter is considered in a reasonable range, e.g. 19-23 $\mathrm{MPa}^{1 / 2}$. Supplementary Information shows the comparison of the CPA model results when asphaltene solubility parameters of 21.51 $\mathrm{MPa}^{1 / 2}$ and $19 \mathrm{MPa}^{1 / 2}$ are used. The heavy component is not self-associating but can crossassociate with the asphaltene component. The asphaltene molecule is treated as having two positive and two negative association sites (four sites in total). The heavy component molecule is treated as having one site, which can associate with all asphaltene molecule sites i.e. regardless of polarity. The cross-association energy $\left(\varepsilon^{23} / R\right)$ between the heavy component and asphaltene molecules is temperature dependent, as shown in Fig. 2 , and is fitted to experimental asphaltene precipitation onset data. The cross-association volume $\left(\beta^{23}\right)$ is kept constant to a value of 0.05 (dimensionless). If the heavy component is divided into multiple components, these components will each have the same value of cross-association 
energy $\left(\varepsilon^{23} / R\right)$ and volume $\left(\beta^{23}\right)$ with asphaltene. The fitted value of $\left(\varepsilon^{23} / R\right)$ in the case of a single heavy component will be different from that in the case of multiple heavy components.

The SRK EoS is described by Soave [26]. For the SRK model, the asphaltene fraction is treated as a monodisperse and non-associating component. The binary interaction parameter $\left(k_{23}\right)$ for the heavy component-asphaltene pair is assumed to be temperature dependent, as shown in Fig. 2, and is fitted to experimental asphaltene precipitation onset data. If the heavy component is divided into multiple components, they each have the same value of $k_{23}$. The fitted value of $k_{23}$ in case of a single heavy component will be different from that in the case of multiple heavy components.

The SRK+HV model is described by Huron and Vidal [27]. For the SRK+HV model, the asphaltene fraction is treated as a monodisperse and non-associating component. The Huron-Vidal mixing rule for energy parameter $(a)$ is defined in equation-1. The Huron-Vidal parameters $\left(G_{23}, G_{32}\right)$ of the heavy component-asphaltene pair are assumed to be temperature dependent, as shown in Fig. 2, and are fitted to experimental asphaltene precipitation onset data. The parameters $\mathrm{g0}_{23}$ and $g 0_{32}$ are assumed to be the same with second order temperature dependency in order to keep three adjustable model parameters as used by the CPA and SRK models. The model results outside the temperature range, used to calculate model parameters, depend upon the selection of temperature dependency (e.g. $A+$ $B T+C / T$ vs. $\left.A+B T+C T^{2}\right)$. The temperature dependency $\left(A+B T+C T^{2}\right)$ is chosen in this work. The parameters $G T_{23}$ and $G T_{32}$ are zero as shown in Table 3. Based on our experience, we fixed the values of $g 0_{33}$ and $g 0_{22}$ to $3000 \mathrm{~K}$ and $1000 \mathrm{~K}$ respectively. If the heavy component is divided into multiple components, they each have the same value of $G_{23}$ and $G_{32}$. The calculated values of $G_{23}$ and $G_{32}$ in case of a single heavy component will be different from those in the case of multiple heavy components.

$$
\begin{gathered}
\frac{a}{b}=\sum_{i} x_{i} \frac{a_{i}}{b_{i}}-\frac{R}{\ln 2} \sum_{i} x_{i} \frac{\sum_{j} x_{j} b_{j} \exp \left(-\alpha_{j i} \frac{G_{j i}}{T}\right) G_{j i}}{\sum_{j} x_{j} b_{j} \exp \left(-\alpha_{j i} \frac{G_{j i}}{T}\right)} \\
G_{j i}=G 0_{j i}+G T_{j i} \times T \\
G 0_{j i}=g 0_{j i}-g 0_{i i}, G T_{j i}=g T_{j i}-g T_{i i} \\
b=\sum_{i} x_{i} b_{i}
\end{gathered}
$$


Please consult the "List of Symbol" and "Greek Letters" sections for the meaning of the symbols used in the equations.

The binary interaction parameters for the CPA and SRK models are shown in Tables 1 and 2 respectively. The binary interaction parameters and Huron-Vidal Parameters for the $\mathrm{SRK}+\mathrm{HV}$ model are shown in Table 3 . For all models, the $k_{\mathrm{ij}}$ parameters for all binary pairs (except those with asphaltene) are obtained from the literature $[15,28]$. The pure component parameters for all models are listed in Table A.1 in Appendix-A.

Table 1

CPA Model: binary interaction parameters $\left(\boldsymbol{k}_{\mathrm{ij}}\right)$.

\begin{tabular}{lcccc}
\hline Component & $\mathrm{N}_{2}{ }^{\mathrm{b}}$ & $\mathrm{CO}_{2}{ }^{\mathrm{b}}$ & $\mathrm{H}_{2} \mathrm{~S}^{\mathrm{b}}$ & Asphaltene $^{\mathrm{c}}$ \\
\hline $\mathrm{N}_{2}$ & 0 & 0 & 0 & 0.44 \\
$\mathrm{CO}_{2}$ & -0.0315 & 0 & 0 & 0.10 \\
$\mathrm{H}_{2} \mathrm{~S}$ & 0.1696 & 0.0989 & 0 & 0 \\
methane & 0.0278 & 0.12 & 0.08 & 0.10 \\
ethane & 0.0407 & 0.12 & 0.0852 & 0.10 \\
propane & 0.0763 & 0.12 & 0.0885 & 0.10 \\
i-butane & 0.0944 & 0.12 & 0.0511 & 0.10 \\
n-butane & 0.07 & 0.12 & 0.06 & 0.10 \\
i-pentane & 0.0867 & 0.12 & 0.06 & 0.10 \\
n-pentane & 0.0878 & 0.12 & 0.0685 & 0.10 \\
heavy comp/s & 0.13 & 0.10 & 0.05 & 0
\end{tabular}

a Same binary parameters are used if we split $\mathrm{C}_{6+}$ fraction into multiple heavy components.

b Values are referred from $[15,28]$.

c Values are fitted in this work. 
Table 2

SRK Model: binary interaction parameters $\left(\boldsymbol{k}_{\mathrm{ij}}\right)$.

\begin{tabular}{lcccc}
\hline Component & $\mathrm{N}_{2}{ }^{\mathrm{b}}$ & $\mathrm{CO}_{2} \mathrm{~b}^{\mathrm{n}}$ & $\mathrm{H}_{2} \mathrm{~S}^{\mathrm{b}}$ & Asphaltene $^{\mathrm{c}}$ \\
\hline $\mathrm{N}_{2}$ & 0 & 0 & 0 & 0.33 \\
$\mathrm{CO}_{2}$ & -0.0315 & 0 & 0 & 0.22 \\
$\mathrm{H}_{2} \mathrm{~S}$ & 0.1696 & 0.0989 & 0 & 0 \\
methane & 0.0278 & 0.12 & 0.08 & 0.165 \\
ethane & 0.0407 & 0.12 & 0.0852 & 0.165 \\
propane & 0.0763 & 0.12 & 0.0885 & 0.165 \\
i-butane & 0.0944 & 0.12 & 0.0511 & 0.165 \\
n-butane & 0.07 & 0.12 & 0.06 & 0.165 \\
i-pentane & 0.0867 & 0.12 & 0.06 & 0.165 \\
n-pentane & 0.0878 & 0.12 & 0.068 & 0.165 \\
heavy comp/s & 0.13 & 0.10 & 0.05 & MAPd \\
\hline
\end{tabular}

a Same binary parameters are used if we split $\mathrm{C}_{6+}$ fraction into multiple heavy components.

${ }^{b}$ Values are referred from $[15,28]$.

${ }^{c}$ Values are fitted in this work.

${ }^{\mathrm{d}}$ Model Adjustable Parameter: calculated value shown in Table 6.

\section{Table 3}

SRK+HV Model: binary interaction $\left(\boldsymbol{k}_{\boldsymbol{i} j}\right)$ and Huron-Vidal parameters.

\begin{tabular}{lcccccccc}
\hline Component & $\mathrm{N}_{2}{ }^{\mathrm{b}}$ & $\mathrm{CO}_{2}{ }^{\mathrm{b}}$ & $\mathrm{H}_{2} \mathrm{~S}^{\mathrm{b}}$ & \multicolumn{5}{c}{ Asphaltene Huron-Vidal Parameters } \\
& & $\mathrm{k}_{\mathrm{ij}}$ & & $\mathrm{G} 0_{\mathrm{ij}}$ & $\mathrm{G}_{\mathrm{ji}}$ & $\mathrm{GT}_{\mathrm{ij}}$ & $\mathrm{GT}_{\mathrm{ji}}$ & $\alpha_{\mathrm{ij}}=\alpha_{\mathrm{ji}}$ \\
\hline $\mathrm{N}_{2}$ & 0 & 0 & 0 & -545.50 & 530.50 & 0 & 0 & 0.2 \\
$\mathrm{CO}_{2}$ & -0.0315 & 0 & 0 & -722.20 & 464.80 & 0 & 0 & 0.2 \\
$\mathrm{H}_{2} \mathrm{~S}^{\mathrm{d}}$ & 0.1696 & 0.0989 & 0 & 11082.74 & -648.02 & 0 & 0 & 0 \\
methane & 0.0278 & 0.12 & 0.08 & 344.59 & -141.79 & -0.5838 & 0.5963 & 0.2 \\
ethane & 0.0407 & 0.12 & 0.0852 & 569.03 & -56.47 & -1.3984 & 0.7299 & 0.2 \\
propane & 0.0763 & 0.12 & 0.0885 & 618.02 & 697.27 & -1.6996 & -0.3379 & 0.2 \\
i-butane & 0.0944 & 0.12 & 0.0511 & 661.20 & 2077.35 & -1.2871 & -3.0500 & 0.2 \\
n-butane & 0.07 & 0.12 & 0.06 & 661.20 & 2077.35 & -1.2871 & -3.0500 & 0.2 \\
i-pentane & 0.0867 & 0.12 & 0.06 & 4585.06 & -2949.16 & -10.4904 & 12.0512 & 0.2 \\
n-pentane & 0.0878 & 0.12 & 0.0685 & 4585.06 & -2949.16 & -10.4904 & 12.0512 & 0.2 \\
heavy comp/s & 0.13 & 0.10 & 0.05 & MAPe & MAPe & 0 & 0 & 0.2 \\
\hline
\end{tabular}

a Same binary parameters are used if we split $\mathrm{C}_{6+}$ fraction into multiple heavy components.

${ }^{\mathrm{b}}$ Values are referred from $[15,28]$

${ }^{c}$ Values are fitted in this work.

${ }^{d}$ Huron-Vidal mixing rule is reduced to classical mixing rule for $\mathrm{H}_{2} \mathrm{~S}$-ashaltene pair due to lack of experimental data.

e Model Adjustable Parameter: calculated value shown in Table 6. 


\section{Results and Discussion}

In this work, six different reservoir fluids are studied. Tables 4 and 5 show their fluid properties and compositions. The fluids are selected so that there are at least two fluids each with experimental data of hydrocarbon/methane gas injection (Fluid-1, 2 and 6), $\mathrm{N}_{2}$ injection (Fluid-2 and 4) and $\mathrm{CO}_{2} / \mathrm{CO}_{2}$ rich gas injection (Fluid-2, 3 and 5) in order to check the reliability of the models in a wide range of conditions. As discussed in the previous section, each model has three adjustable parameters (see Fig. 2) for the heavy component-asphaltene pair to be fitted to experimental data of asphaltene onset condition at three different temperatures within the range of interest. When experimental data are available at only two temperatures, the third adjustable parameter is set to zero. The calculated parameters of each model are shown in Table 6. Three upper onset pressures and one saturation pressure are used to calculate the model parameters for Fluids-1, 2, 4, and 6, whereas only two upper onset pressures (due to lack of data) and one saturation pressure are used for Fluids-3 and 5 . The binary parameters for gas/alkane-asphaltene pairs are optimized with respect to UOP data assuming an asphaltene fraction of $0.1 \mathrm{~mol} \%$ of the $C_{6+}$ fraction for all fluids. For example, binary parameter for $\mathrm{N}_{2}$-asphaltene pair is optimized from the UOP data of Fluids-2 and 4 with $\mathrm{N}_{2}$ gas injection. The value of $0.1 \mathrm{~mol} \%$ asphaltene fraction is selected so that the calculated value of Fluid-6 asphaltene $\mathrm{MW}$ is not lower than the minimum value (300 Da) of experimentally measured asphaltene MW [29]. One can also optimize the binary parameters and study the models considering different amount of asphaltene (for example $0.3 \mathrm{~mol} \%$ in the $\mathrm{C}_{6+}$ fraction); however, the results are not shown in this work. The calculated parameters $\left(T_{C}, P_{C}, \omega\right)$ of the heavy component, after tuning the critical pressure with respect to bubble pressure of reservoir fluid, are listed in Table A.2 of Appendix-A. For all fluids, there are sufficient experimental data so that the model can be correlated with experimental data for a single gas injection amount, and then the model reliability can be evaluated by comparing the model predictions with experimental data for different amounts of gas injection. For example, as shown in Fig. 3, the model can be fitted to the $5 \mathrm{~mol} \%$ gas injection scenario and then the model predictions can be validated against the 0,15 and 30 mol\% gas injection scenarios. 
Table 4

Properties of all fluids used in this work.

\begin{tabular}{|c|c|c|c|c|c|c|}
\hline & $\begin{array}{c}\text { Fluid-1 } \\
{[14]}\end{array}$ & $\begin{array}{c}\text { Fluid-2 } \\
\text { [30] }\end{array}$ & $\begin{array}{c}\text { Fluid-3 } \\
\text { [31] }\end{array}$ & $\begin{array}{c}\text { Fluid-4 } \\
\text { [32] }\end{array}$ & $\begin{array}{c}\text { Fluid-5 } \\
\text { [33] }\end{array}$ & $\begin{array}{c}\text { Fluid-6 } \\
\text { [31] }\end{array}$ \\
\hline Saturates (wt\%) & 66.26 & 39.2 & a & 57.4 & $\mathrm{~b}$ & 73.42 \\
\hline Aromatics (wt\%) & 25.59 & 35.9 & a & 30.8 & b & 19.32 \\
\hline Resins (wt\%) & 5.35 & 9.0 & a & 10.4 & $\mathrm{~b}$ & 7.05 \\
\hline Asphaltenes (wt\%) & 2.8 & 15.5 & 0.17 & 1.4 & $1.4^{\mathrm{c}}$ & 0.17 \\
\hline $\mathrm{C}_{6+} \mathrm{MW}(\mathrm{Da})$ & 208.6 & 250.6 & - & 225.7 & 223.2 & 191.1 \\
\hline STO MW (Da) & 193 & 289.9 & 212.9 & 229.2 & - & 182 \\
\hline STO SG (-) & 0.823 & 0.919 & 0.846 & 0.865 & 0.863 & 0.817 \\
\hline MW of reservoir fluid (Da) & 97.8 & 132.9 & 75.4 & 102.0 & 102.6 & 92.8 \\
\hline $\operatorname{GOR}\left(m^{3} / m^{3}\right)$ & 140 & 160 & - & 160 & 140 & 152 \\
\hline
\end{tabular}

a SARA values for fluid-3 are not mentioned since there is a mismatch between Tables 5 and A3 of reference [31]. ${ }^{b}$ SARA values for fluid-5 are not available. ${ }^{c}$ asphaltene amount is assumed.

Table 5

Composition of reservoir fluids used in this work for the evaluation of the CPA, SRK and SRK-HV models *.

\begin{tabular}{|c|c|c|c|c|c|c|}
\hline & $\begin{array}{c}\text { Fluid-1 } \\
\text { [14] }\end{array}$ & $\begin{array}{c}\text { Fluid-2 } \\
\text { [30] }\end{array}$ & $\begin{array}{c}\text { Fluid-3 } \\
\text { [31] }\end{array}$ & $\begin{array}{c}\text { Fluid-4 } \\
\text { [32] }\end{array}$ & $\begin{array}{c}\text { Fluid-5 } \\
\text { [33] }\end{array}$ & $\begin{array}{l}\text { Fluid-6 } \\
\text { [31] }\end{array}$ \\
\hline Comp. & $\mathrm{mol} \%$ & mol\% & mol\% & mol\% & $\mathrm{mol} \%$ & mol\% \\
\hline $\mathrm{N}_{2}$ & 0.163 & 0.340 & 0.090 & 0.496 & 0.390 & 0.147 \\
\hline $\mathrm{CO}_{2}$ & 1.944 & 0.160 & 3.679 & 11.374 & 0.840 & 1.711 \\
\hline $\mathrm{H}_{2} \mathrm{~S}$ & 0.000 & 0.000 & 5.267 & 3.218 & 0.000 & 0.000 \\
\hline methane & 33.600 & 32.900 & 45.840 & 27.350 & 36.630 & 32.508 \\
\hline ethane & 7.674 & 8.150 & 5.350 & 9.445 & 8.630 & 7.966 \\
\hline propane & 7.283 & 6.280 & 4.214 & 7.053 & 6.660 & 7.700 \\
\hline i-butane & 1.886 & 0.000 & 5.163 & 0.948 & 1.210 & 1.930 \\
\hline$n$-butane & 5.671 & 1.130 & 2.792 & 3.675 & 3.690 & 4.661 \\
\hline$i$-pentane & 2.194 & 0.000 & 1.393 & 1.388 & 1.550 & 2.076 \\
\hline$n$-pentane & 2.981 & 3.500 & 1.802 & 2.061 & 2.250 & 2.749 \\
\hline $\mathrm{C}_{6+}$ & 36.604 & 47.540 & 24.410 & 32.993 & 38.150 & 38.553 \\
\hline
\end{tabular}

${ }^{*} C_{6+} \mathrm{mol} \%$ is the sum of $\mathrm{mol} \%$ of heavy component/s and asphaltene. 
Table 6

Calculated values of the model parameters (see Fig. 2) for the CPA, SRK and SRK+HV for all fluids.

\begin{tabular}{|c|c|c|c|c|c|c|c|c|c|c|}
\hline \multirow{3}{*}{ Fluid } & \multirow{3}{*}{$\begin{array}{l}\text { Asp MW } \\
\text { (Da) }\end{array}$} & \multicolumn{9}{|c|}{ Model Adjustable Parameters (see Fig. 2) for heavy component/s (2)-asphaltene(3) pair/s } \\
\hline & & \multicolumn{3}{|c|}{$\begin{array}{c}\text { CPA } \\
\varepsilon^{23} / R=A+B T+C / T(\text { in } K)\end{array}$} & \multicolumn{3}{|c|}{$\begin{array}{c}\mathrm{SRK} \\
k_{23}=A+B T+C / T\end{array}$} & \multicolumn{3}{|c|}{$\begin{array}{c}\text { SRK }+\mathrm{HV} \\
g 0_{23}=g 0_{32}=A+B T+C T^{2}(\text { in } K)\end{array}$} \\
\hline & & A & B & C & A & B & C & A & B & C \\
\hline \multirow{3}{*}{ Fluid-1 } & 6165 & 3232 & -2.0513 & -233132 & -0.7908 & 0.0015 & 102.63 & 7558 & -27.90 & 0.0499 \\
\hline & 750 & 2674 & -0.5998 & -142291 & -0.6408 & 0.0010 & 84.50 & 4847 & -12.77 & 0.0204 \\
\hline & 10000 & 3341 & -2.3771 & -247603 & -0.8488 & 0.0016 & 110.82 & 10475 & -45.73 & 0.0799 \\
\hline \multirow{2}{*}{ Fluid-2 } & 38500 & 3606 & -3.5623 & -284768 & -0.5081 & 0.0011 & 60.46 & 31.97 & -0.1063 & 0.0001 \\
\hline & 750 & 3048 & -1.3732 & -181089 & -0.3991 & 0.0007 & 46.97 & 26.71 & -0.0922 & 0.0001 \\
\hline \multirow{2}{*}{ Fluid-3 } & 372 & 1770 & 0.1749 & 0 & -0.2654 & 0.0008 & 0.00 & 0.00 & 256.05 & 8.3278 \\
\hline & 10000 & 2246 & -2.1483 & 0 & -0.3830 & 0.0014 & 0.00 & $N A^{b}$ & $N A^{b}$ & $N A^{b}$ \\
\hline \multirow{3}{*}{ Fluid-4 } & 3450 & 8097 & -8.6298 & -1210194 & -1.1939 & 0.0020 & 189.23 & 16059 & -72.79 & 0.1097 \\
\hline & 750 & 6680 & -6.1582 & -963365 & -1.1186 & 0.0018 & 183.19 & 8082 & -29.04 & 0.0434 \\
\hline & 10000 & 9599 & -11.1237 & -1469333 & -1.2612 & 0.0022 & 196.13 & $N A^{b}$ & $N A^{b}$ & $N A^{b}$ \\
\hline \multirow{3}{*}{ Fluid-5 } & 3100 & 1475 & 0.6444 & 0 & -0.1376 & 0.0005 & 0.00 & 0.00 & 2461.10 & 4.1084 \\
\hline & 750 & 1406 & 1.2351 & 0 & -0.0921 & 0.0003 & 0.00 & 0.00 & 3267.62 & -0.2775 \\
\hline & 10000 & 1538 & 0.1227 & 0 & -0.1742 & 0.0007 & 0.00 & $N A^{b}$ & $N A^{b}$ & $N A^{b}$ \\
\hline \multirow{2}{*}{ Fluid-6 } & 330 & 2962 & -1.7953 & -195514 & -0.7345 & 0.0014 & 94.77 & 6063 & -20.95 & 0.0397 \\
\hline & 10000 & 5834 & -7.3187 & -644148 & -1.0292 & 0.0022 & 131.70 & $N A^{b}$ & $N A^{b}$ & $N A^{b}$ \\
\hline $\begin{array}{l}\text { Fluid-1 } 1^{a} \\
(9 \mathrm{HC})\end{array}$ & 6165 & 2861 & -1.3244 & -185970 & -0.7524 & 0.0014 & 98.47 & 6853 & -23.66 & 0.0416 \\
\hline
\end{tabular}

${ }^{a}$ Fluid-1 $C_{6+}$ is divided into nine heavy components and asphaltene.

b SRK+HV model parameters could not be calculated for this case.

Table 7

Injected gas composition in mol\% for Fluids-1, 5 and 6.

\begin{tabular}{lccc}
\hline Components & Fluid-1 & Fluid-5 & Fluid-6 \\
{$[31]$} & {$[33]$} & 0.462 \\
$\mathrm{~N}_{2}$ & {$[14]$} & 0.000 & 4.510 \\
$\mathrm{CO}_{2}$ & 0.398 & 60.320 & 0.000 \\
$\mathrm{H}_{2} \mathrm{~S}$ & 3.891 & 0.000 & 87.449 \\
methane & 0.000 & 10.730 & 7.192 \\
ethane & 71.312 & 7.550 & 0.370 \\
propane & 11.912 & 9.090 & 0.006 \\
isobutane & 7.224 & 0.000 & 0.005 \\
nbutane & 1.189 & 6.470 & 0.001 \\
isopentane & 2.254 & 0.030 & 0.001 \\
npentane & 0.567 & 5.820 & 0.003 \\
$C_{6+}$ & 0.616 & 0.000 & 0.003 \\
\hline
\end{tabular}

Page 11 of 31 
Fig. 3 shows that all three models can correlate the 5 mol\% gas injection scenario for Fluid1 with $0.1 \mathrm{~mol} \%$ of asphaltene in $\mathrm{C}_{6+}$ fraction. The composition of the injected hydrocarbon (H/C) gas is given in Table 7. Fig. 3 shows that there is considerable deviation for the 0 mol\% $\mathrm{H} / \mathrm{C}$ gas injection scenario while deviations for the 15 and $30 \mathrm{~mol} \%$ scenarios are smaller. The CPA predictions are very different to those of the SRK and SRK+HV outside of the experimental temperature range used in the parameters fitting. The bubble pressure predictions are almost identical for all three models. Table 8 shows the relative deviation in UOP for fluid-1 for three different asphaltene molecular weights $(750,6165$ and $10000 \mathrm{Da})$ at $347 \mathrm{~K}$. The asphaltene molecular weight of $6165 \mathrm{Da}$ corresponds to $0.1 \mathrm{~mol} \%$ of asphaltene in $C_{6+}$ fraction. Table 8 shows that the relative deviations for the CPA model are almost the same for all three cases of asphaltene molecular weights and therefore the CPA model is not very sensitive to the asphaltene molecular weight. This insensitivity is due to the association term. At upper onset pressure, asphaltene rich phase is in equilibrium with asphaltene lean phase. Each phase can be analyzed with respect to the SRK and association terms contribution in case of the CPA model. The association term contribution for asphaltene lean phase is negligible compared to the SRK term contribution due to minor fraction of asphaltene component. The contribution of the association term for asphaltene rich phase remains almost the same at upper onset pressure for different MW cases by calculating the corresponding cross-association energy $\left(\varepsilon^{23} / R\right)$ as shown in Table 6 . In simple words, asphaltene rich phase molar composition remains almost the same for different MW cases which imparts the relative insensitivity with respect to MW. More details about the CPA model behavior can also be found in our previous work [18]. The relative deviations for the SRK and SRK +HV models are different for all three cases of asphaltene molecular weights and therefore these models are sensitive to the asphaltene molecular weight in case of $\mathrm{H} / \mathrm{C}$ gas injection. Panuganti et al [14] also studied Fluid-1 with the SRK EoS using the PVT-Sim software from Calsep [34] and concluded that the SRK EoS is unable to predict the gas injection effect correctly. They [14] characterized Fluid-1 and fitted the parameters to match the saturation pressures and asphaltene onset pressures for different temperatures with the 5 mol\% gas injection scenario. Since our modeling approach with the SRK EoS can predict the gas injection effect correctly, we believe this shows that the modeling assumptions and model parameters are very important. 


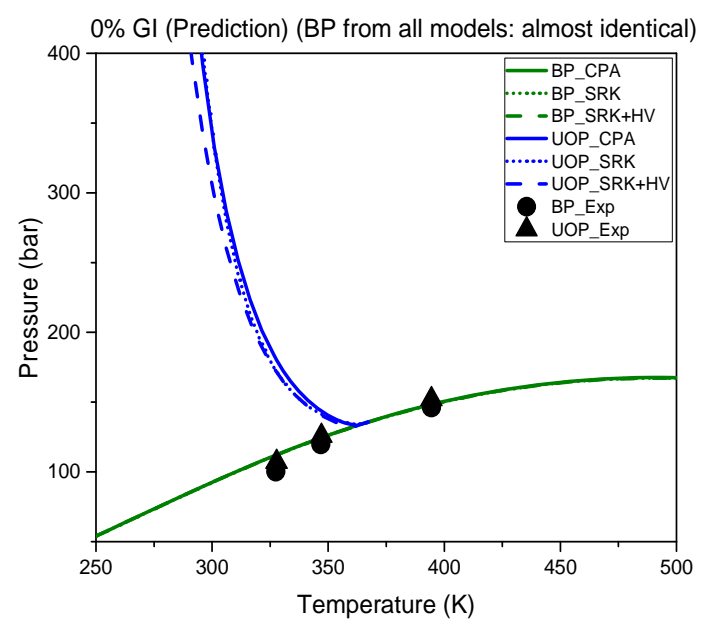

(a)

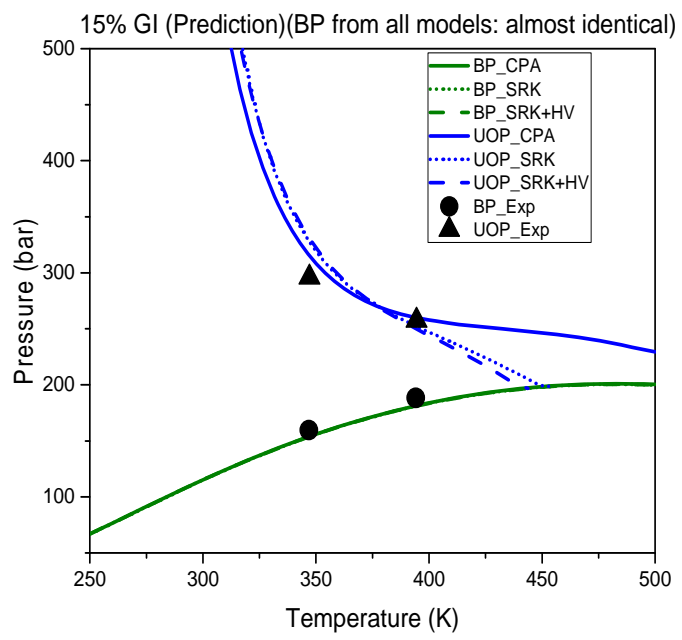

(c)

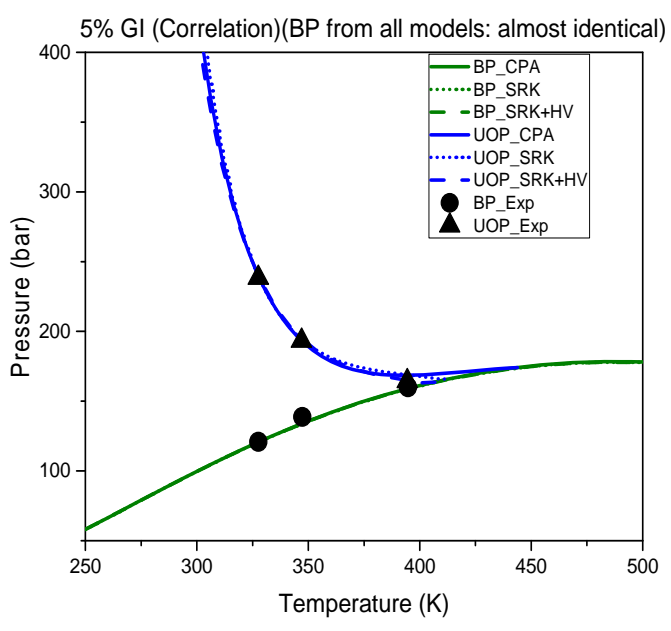

(b)

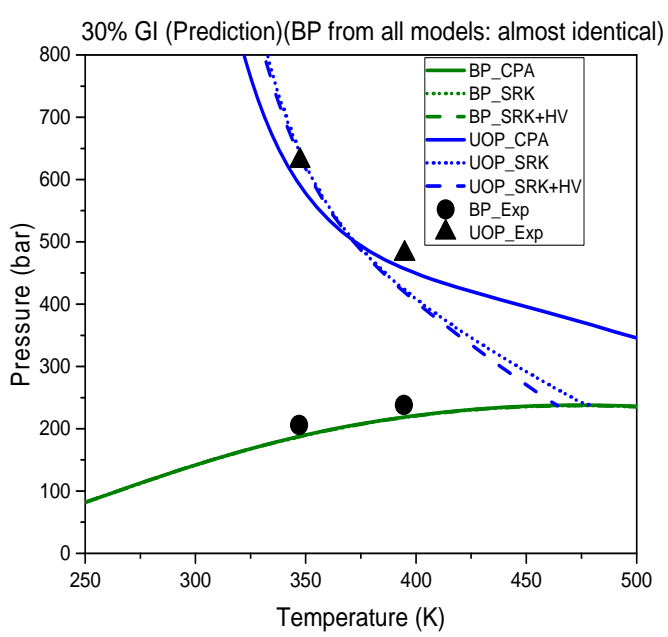

(d)

Fig. 3. Fluid-1: Upper onset and bubble pressure boundaries for reservoir fluid without gas injection (Fig. 3a) and with gas injection of $5 \mathrm{~mol} \%$ (Fig. 3b), $15 \mathrm{~mol} \%$ (Fig. 3c), $30 \mathrm{~mol} \%$ (Fig. 3d). Symbols represent experimental data from Panuganti et al [14] and lines represent results from all the three models. Asphaltene amount in $\boldsymbol{C}_{6+}$ fraction is $0.1 \mathrm{~mol} \%$. 
Table 8

Fluid-1: Relative Deviation (RD) in calculated Upper Onset Pressure (UOP) with respect to experimental data for different amounts of gas injection and considering different asphaltene molecular weights.

\begin{tabular}{|c|c|c|c|c|c|c|}
\hline \multirow{2}{*}{ Fluid } & \multirow{2}{*}{$\begin{array}{c}\text { Temp. } \\
\mathrm{K}\end{array}$} & \multirow{2}{*}{$\begin{array}{c}\text { Gas Inj. } \\
\text { mol\% }\end{array}$} & \multirow{2}{*}{$\begin{array}{c}\mathrm{MW} \\
\mathrm{Da}\end{array}$} & \multicolumn{3}{|c|}{ Relative Deviation (\%) ${ }^{\mathrm{b}}$} \\
\hline & & & & CPA & SRK & $\mathrm{SRK}+\mathrm{HV}$ \\
\hline \multirow{4}{*}{1} & \multirow{4}{*}{347} & \multirow{4}{*}{$\begin{array}{c}30 \\
(H / C \text { gas })\end{array}$} & 750 & 6 & -16 & -9 \\
\hline & & & $6165^{a}$ & 6 & -3 & -1 \\
\hline & & & 10000 & 6 & 2 & $\overline{7}$ \\
\hline & & & $A A D^{c}$ & 6 & 7 & 6 \\
\hline \multirow{7}{*}{2} & \multirow{7}{*}{311} & \multirow{2}{*}{$\begin{array}{c}10 \\
\left(\mathrm{~N}_{2}\right)\end{array}$} & 750 & 14 & 13 & 8 \\
\hline & & & $38500^{a}$ & 10 & 7 & 5 \\
\hline & & \multirow{2}{*}{$\begin{array}{c}10 \\
\left(\mathrm{CO}_{2}\right)\end{array}$} & 750 & 9 & -10 & -36 \\
\hline & & & $38500^{a}$ & 6 & 0 & -3 \\
\hline & & \multirow{3}{*}{$\begin{array}{c}10 \\
\text { (methane) }\end{array}$} & 750 & 11 & -6 & -17 \\
\hline & & & $38500^{a}$ & 8 & -6 & -67 \\
\hline & & & $A A D^{c}$ & 10 & 7 & 22 \\
\hline \multirow{3}{*}{3} & \multirow{3}{*}{355} & \multirow{3}{*}{$\begin{array}{c}30 \\
\left(\mathrm{CO}_{2}\right)\end{array}$} & $372^{A}$ & -4 & -4 & -6 \\
\hline & & & 10000 & -3 & 17 & $N A^{d}$ \\
\hline & & & $\mathrm{AAD}^{\mathrm{C}}$ & 3 & 10 & 6 \\
\hline \multirow{4}{*}{4} & \multirow{4}{*}{419} & \multirow{4}{*}{$\begin{array}{c}20 \\
\left(\mathrm{~N}_{2}\right)\end{array}$} & 750 & 2 & -1 & -27 \\
\hline & & & $3450^{a}$ & 0 & 0 & 1 \\
\hline & & & 10000 & -2 & 1 & $N A^{d}$ \\
\hline & & & $A A D^{c}$ & 1 & 1 & 14 \\
\hline \multirow{4}{*}{5} & \multirow{4}{*}{363} & \multirow{4}{*}{$\begin{array}{c}25 \\
\left(\mathrm{CO}_{2} \text { rich gas }\right)\end{array}$} & 750 & -4 & -15 & -28 \\
\hline & & & $3100^{a}$ & -5 & -1 & -8 \\
\hline & & & 10000 & -4 & 12 & $N A^{d}$ \\
\hline & & & $A A D^{c}$ & 4 & 9 & 18 \\
\hline \multirow{3}{*}{6} & \multirow{3}{*}{348} & 30 & $330^{a}$ & 0 & -8 & -13 \\
\hline & & (H/C gas) & 10000 & 1 & 19 & $N A^{d}$ \\
\hline & & & $A A D^{c}$ & 0 & 13 & 6 \\
\hline \multirow[t]{2}{*}{$\begin{array}{c}1 \\
\text { (with } 9 \mathrm{HC} \text { ) }\end{array}$} & 347 & $\begin{array}{c}30 \\
\text { (H/C gas) }\end{array}$ & 6165 & 7 & -3 & -1 \\
\hline & & & $A A D^{c}$ & 5 & 7 & 15 \\
\hline
\end{tabular}

\footnotetext{
${ }^{\text {a }}$ Molecular weight corresponds to 0.1 mol\% of asphaltene amount in $C_{6+}$ fraction.

${ }^{\mathrm{b}}$ Relative Deviation $(\mathrm{RD})=\frac{U O P^{\exp }-U O P^{\text {calc }}}{U O P^{\exp }} \times 100$

${ }^{c}$ Average Absolute Deviation (AAD) $=\sum_{i}^{N}\left|R D_{i}\right|$, where $\left|R D_{i}\right|$ is the absolute value of RD of point $i, N$ is a total number points.

${ }^{d} \mathrm{SRK}+\mathrm{HV}$ model parameters could not be calculated for this case.
} 
Fluid-2 contains the most asphaltene of the fluids studied, $15.5 \mathrm{wt} \%$ in stock tank oil, making it possible to check the effect of asphaltene concentration on the models. Fig. 4 shows that all three models can correlate the experimental data of reservoir fluid without gas injection with 0.1 mol\% of asphaltene in $\mathrm{C}_{6+}$ fraction. The models' predictions are very different at higher temperature beyond the experimental range used in the parameters' estimation. It can be observed that the SRK+HV model gives highly non-linear behavior at high temperatures outside of the experimental temperature range. Fig. 4 shows that all three models have minor deviations when 10 mol\% of $\mathrm{N}_{2}$ or $\mathrm{CO}_{2}$ gas are added. The CPA and SRK models have minor deviations when $10 \mathrm{~mol} \%$ of methane gas is added, whereas the $\mathrm{SRK}+\mathrm{HV}$ has considerable deviations. There are experimental data of UOP with HC gas (methane rich gas) injection for Fluids-1 and 6. However, the difference in experimental data of UOP (Tables A.3 and A.8), fluid composition (Table 5) and injected HC gas composition (Table 7 ) between Fluids- 1 and 2 are relatively small compared to those between Fluids-1 or 6 and 2. Therefore, it is believed that the poor performance of the SRK+HV model in case of methane injection is due to improper HV parameters for alkane-asphaltene binary pairs. In addition, if the SRK+HV gives poor results one should be suspicious and check using SRK as it is the baseline for the SRK+HV. Table 8 shows relative deviations in UOP prediction for fluid-2 using two different asphaltene molecular weights (750 and $38500 \mathrm{Da})$ at $311 \mathrm{~K}$. The asphaltene molecular weight of $38500 \mathrm{Da}$ corresponds to $0.1 \mathrm{~mol} \%$ of asphaltene in $\mathrm{C}_{6+}$ fraction. Like Fluid-1, the relative deviations for the CPA model are almost same for the two cases of asphaltene molecular weights. The relative deviations for the SRK model are not very sensitive to asphaltene molecular weight when $10 \mathrm{~mol} \% N_{2}$ or methane is added but they are relatively sensitive when $10 \mathrm{~mol} \% \mathrm{CO}_{2}$ is added. The relative deviation for different MW cases during a gas injection depends upon the asphaltene rich phase composition at upper onset pressure (both before and after gas injection) for a given temperature and binary interaction parameter $\left(k_{\mathrm{ij}}\right)$ of gas-asphaltene pair. Similarly, the relative deviations for the $\mathrm{SRK}+\mathrm{HV}$ model are not very sensitive to asphaltene molecular weight when $10 \mathrm{~mol} \% \mathrm{~N}_{2}$ is added but they are relatively sensitive when $10 \mathrm{~mol} \% \mathrm{CO}_{2}$ or methane is added. These results show that the difference between relative deviations, for the SRK or SRK+HV, would increase with the amount of injected gas for different asphaltene molecular weights. 
$0 \%$ Gas Inj. (Correlation)
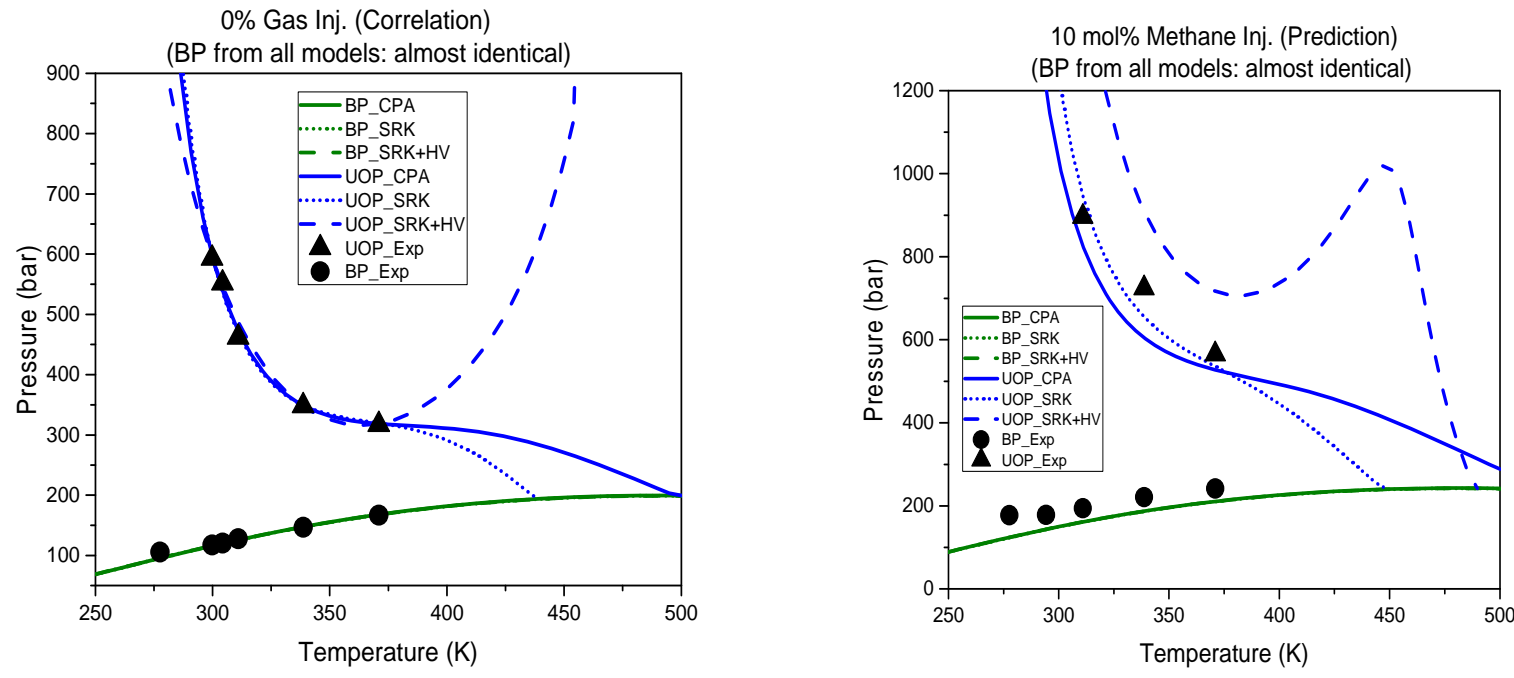

(a)

(b)
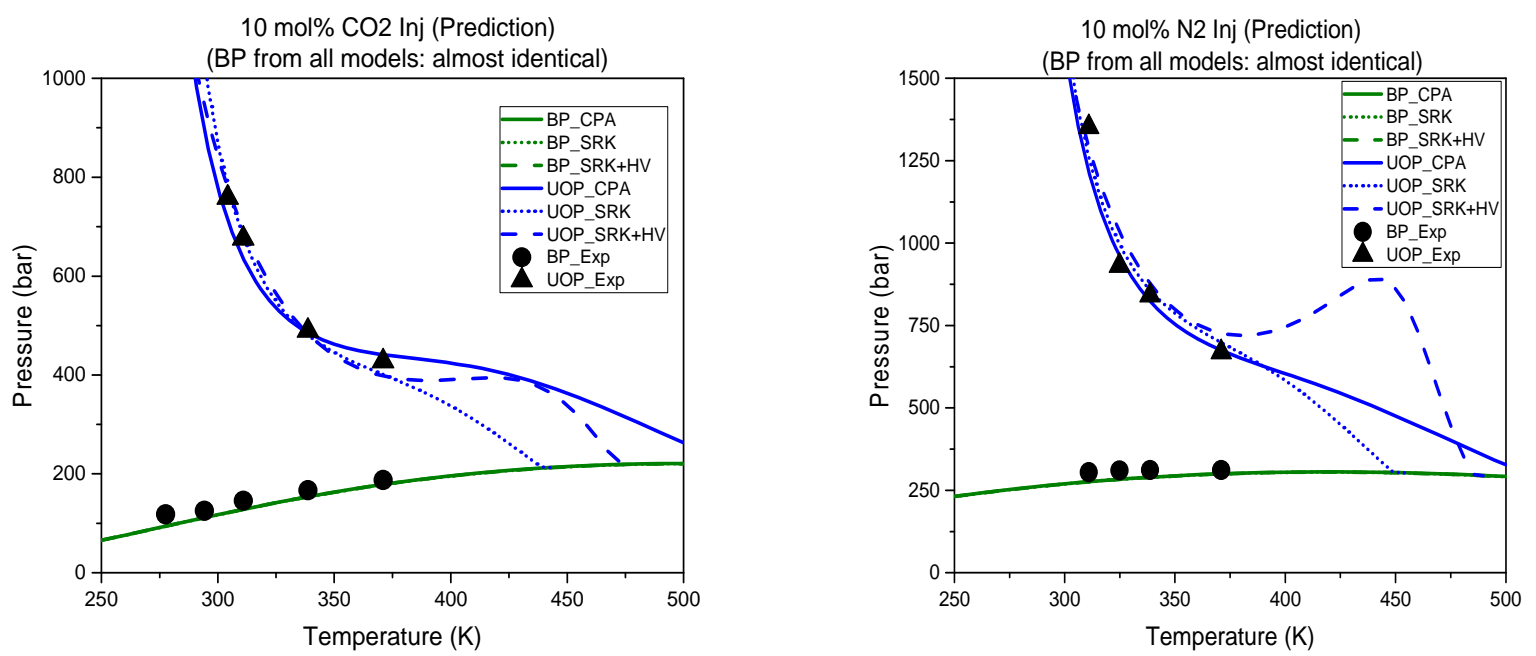

(c)

(d)

Fig. 4. Fluid-2: Upper onset and bubble pressure boundaries for reservoir fluid without gas injection (Fig. 4a) and with gas injection of 10 mol\% methane (Fig. 4b), 10 mol\% $\mathbf{C O}_{2}$ (Fig. 4c) and $10 \mathrm{~mol} \% \mathbf{N}_{2}$ (Fig. 4d). Symbols represent experimental data from Gonzalez et al [30] and lines represent results from all the three models. Asphaltene amount in $\mathbf{C}_{6+}$ fraction is $0.1 \mathrm{~mol} \%$.

Fig. 5 shows that all three models can correlate the experimental data of Fluid- 3 with 20 mol\% $\mathrm{CO}_{2}$ gas injection but the correlations are very different at temperatures beyond the experimental range used in the parameters' estimation. It can be observed that the SRK model gives highly non-linear behavior at temperatures (around 250-260 K) beyond the experimental range. Fig. 5 shows that all three models have minor deviations when $30 \mathrm{~mol} \%$ of $\mathrm{CO}_{2}$ gas is added. Table 8 shows the relative deviations in UOP predictions for fluid-3 using 
two different asphaltene molecular weights (372 and $10000 \mathrm{Da}$ ) at $355 \mathrm{~K}$. The asphaltene molecular weight of $372 \mathrm{Da}$ corresponds to $0.1 \mathrm{~mol} \%$ of asphaltene in $\mathrm{C}_{6+}$ fraction. Like the previously mentioned fluids, the relative deviations for the CPA model are almost the same for the two cases of asphaltene molecular weights. The relative deviation for the SRK model is very sensitive to asphaltene molecular weight. The SRK $+\mathrm{HV}$ model could not correlate the data when an asphaltene molecular weight of $10000 \mathrm{Da}$ was used. It is observed that the SRK+HV model can correlate the data when the non-randomness factor $\left(\alpha_{\mathrm{ij}}\right)$ for heavy component-asphaltene pair is changed from 0.2 to $0<\alpha_{\mathrm{ij}}<0.12$. However, it would necessitate the optimization of binary parameters of gas/alkane-asphaltene pairs and therefore the results are not shown in this work. The critical pressure of the heavy component was tuned to the bubble point pressure of Fluid-3 without gas injection.

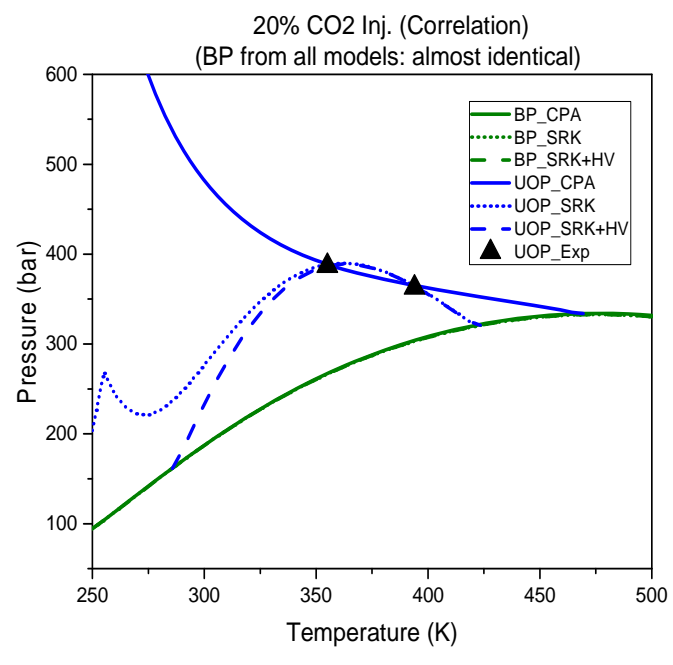

(a)

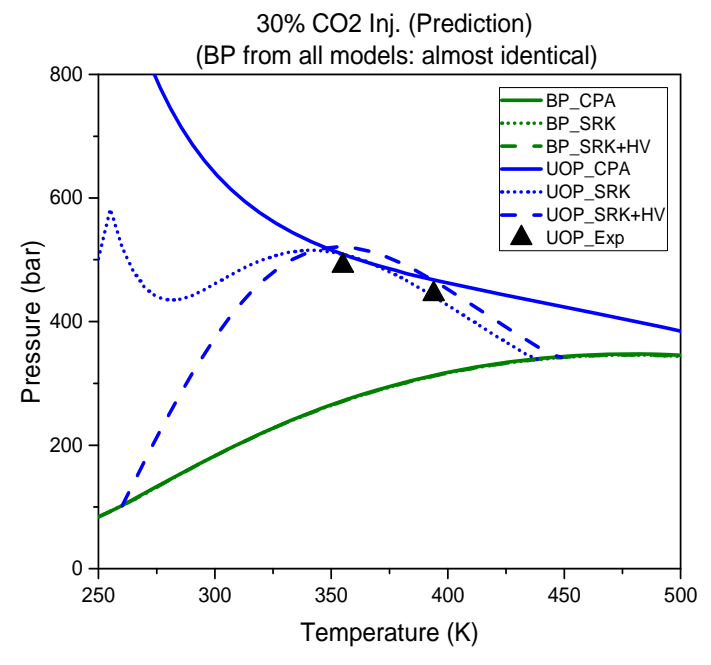

(b)

Fig. 5. Fluid-3: Upper onset and bubble pressure for the reservoir fluid with $\mathbf{C O}_{\mathbf{2}}$ injection of $20 \mathrm{~mol} \%$ (Fig. $5 \mathrm{a}$ ) and $30 \mathrm{~mol} \%$ (Fig. 5b). Symbols represent experimental data from Punnapala et al [31] and lines represent results from all three models. Asphaltene amount in $\boldsymbol{C}_{6+}$ fraction is $0.1 \mathrm{~mol} \%$.

Fig. 6 shows that all three models can correlate the experimental data of Fluid- 4 when there is no gas injection but the correlations are very different at temperatures (around 420$500 \mathrm{~K}$ ) above the experimental range used in the parameters' estimation. The lower onset pressure results are predictions. For the SRK and SRK+HV models, lower onset pressure 
predictions are not shown at higher temperature (around 425-500 K) since these models predict asphaltene precipitation at ambient pressure, possibly due to incorrect convergence. The same behavior was also observed for Fluid-1 (with SRK+HV), Fluids-2 and 5 (with SRK and SRK+HV) but is not shown here. Fig. 6 shows that all three models have minor deviations when $\mathrm{N}_{2}$ gas is added at $419 \mathrm{~K}$. Table 8 shows relative deviations in UOP prediction for Fluid4 for three different asphaltene molecular weights $(750,3450$ and $10000 \mathrm{Da})$ at $419 \mathrm{~K}$. The asphaltene molecular weight of $3450 \mathrm{Da}$ corresponds to $0.1 \mathrm{~mol} \%$ of asphaltene in $C_{6+}$ fraction. The relative deviations for the CPA and SRK models are almost the same for all three cases of asphaltene molecular weights. The relative deviation for the SRK $+\mathrm{HV}$ is relatively sensitive to the asphaltene molecular weight. The SRK+HV model could not correlate the data when an asphaltene molecular weight of $10000 \mathrm{Da}$ was used.

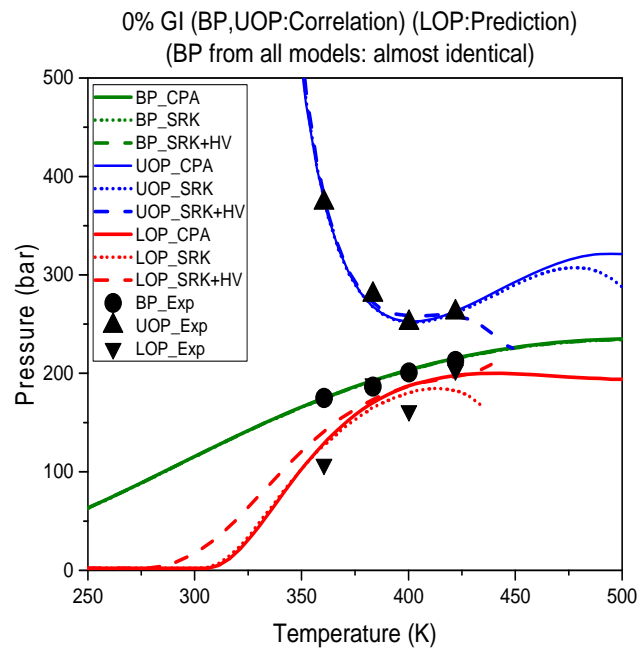

(a)

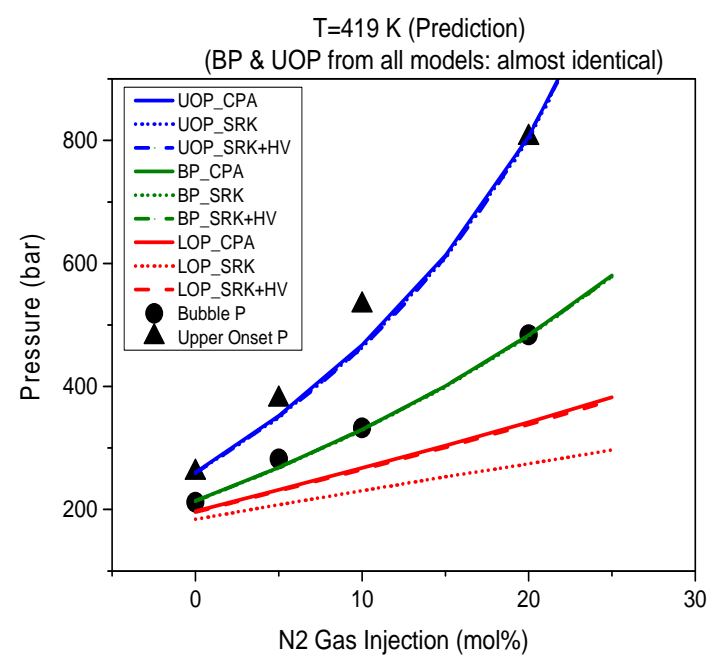

(b)

Fig. 6. Fluid-4: Upper onset, lower onset and bubble pressure boundaries for reservoir fluid without gas injection (Fig. 6a). (Fig. 6b) Effect of $\mathbf{N}_{2}$ injection on upper onset, lower onset and bubble pressure boundaries at $419 \mathrm{~K}$. Symbols represent experimental data from Jamaluddin et al [32] and lines represent results from all the three models. Asphaltene amount in $\mathbf{C}_{6+}$ fraction is $0.1 \mathrm{~mol} \%$.

Fig. 7 shows that all three models can correlate the experimental data of Fluid- 5 when there is no gas injection and $10 \mathrm{~mol} \% \mathrm{CO}_{2}$ rich gas injection. It shows that all three models have minor deviations when 15 and $25 \mathrm{~mol} \% \mathrm{CO}_{2}$ rich gas is added at $363 \mathrm{~K}$. The composition of injected gas is given in Table 7. Table 8 shows the relative deviation in UOP for Fluid-5 using three different asphaltene molecular weights (750, 3100 and $10000 \mathrm{Da})$ at $363 \mathrm{~K}$. The asphaltene molecular weight of $3100 \mathrm{Da}$ corresponds to $0.1 \mathrm{~mol} \%$ of asphaltene 
in $\mathrm{C}_{6+}$ fraction. Similarly to other previously mentioned fluids, the relative deviations for the CPA model are almost the same for the three cases of asphaltene molecular weights. The relative deviations for the $\mathrm{SRK}$ and $\mathrm{SRK}+\mathrm{HV}$ models are very sensitive to the asphaltene molecular weight. The SRK+HV model could not correlate the data when the asphaltene molecular weight of 10000 Da was used.

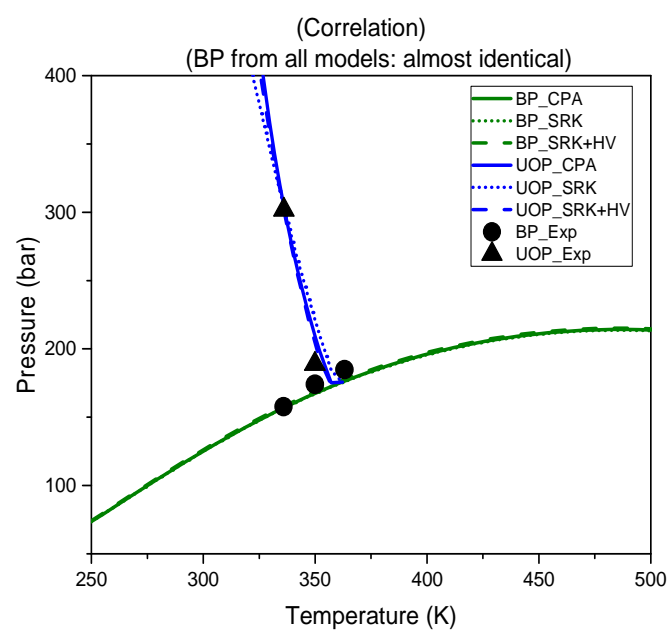

(a)

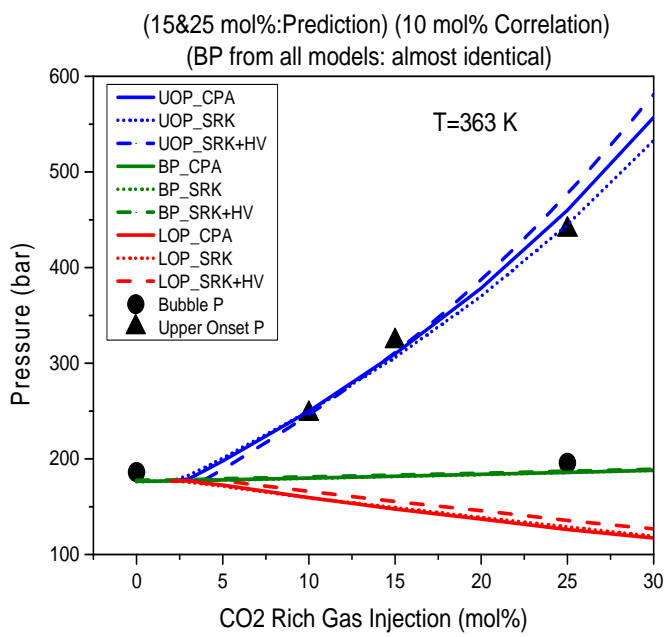

(b)

Fig. 7. Fluid-5: Upper onset and bubble pressure boundaries for reservoir fluid without gas injection (Fig. 7a). (Fig. 7b) Effect of $\mathbf{C O}_{2}$ rich gas injection on upper onset, lower onset and bubble pressure boundaries at 363K. Symbols represent experimental data from Memon et al [33] and lines represent results from all the three models. Asphaltene amount in $\mathbf{C}_{6+}$ fraction is $0.1 \mathrm{~mol} \%$.

Fig. 8 shows that all three models can correlate the experimental data of Fluid- 6 when 10 $\mathrm{mol} \% \mathrm{H} / \mathrm{C}$ gas is injected. It shows that all three models have minor deviations when 15 and $30 \mathrm{~mol} \% \mathrm{H} / \mathrm{C}$ gas are added. The composition of injected H/C gas is mentioned in Table 7. Table 8 shows the relative deviation in UOP for fluid-6 using two different asphaltene molecular weights (330 and $10000 \mathrm{Da}$ ) at $348 \mathrm{~K}$. The asphaltene molecular weight of $330 \mathrm{Da}$ corresponds to $0.1 \mathrm{~mol} \%$ of asphaltene in $\mathrm{C}_{6+}$ fraction. Similarly to other previously mentioned fluids, the relative deviations for the CPA model are almost the same for the two cases of asphaltene molecular weights. The relative deviation for the SRK model is once again very sensitive to the asphaltene molecular weight. The SRK+HV model could not correlate the data when the asphaltene molecular weight of 10000 Da was used, which was the case for several of the previously studied fluids. 
10 mol\% GI (Correlation)

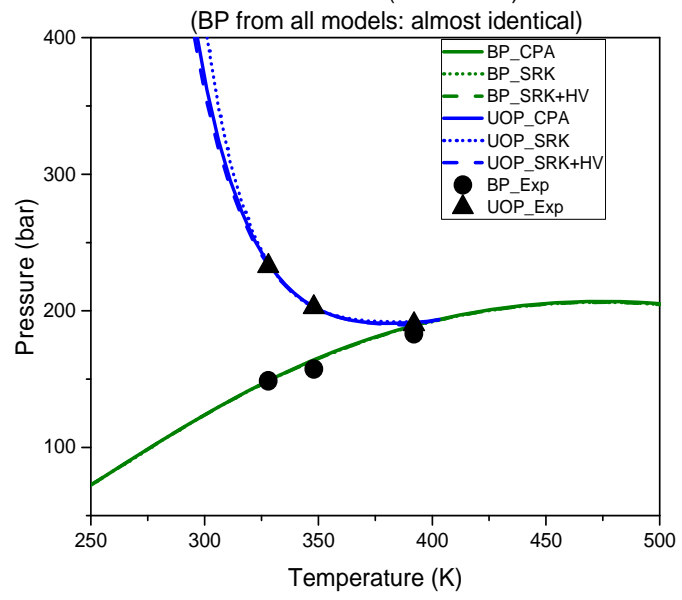

(a)

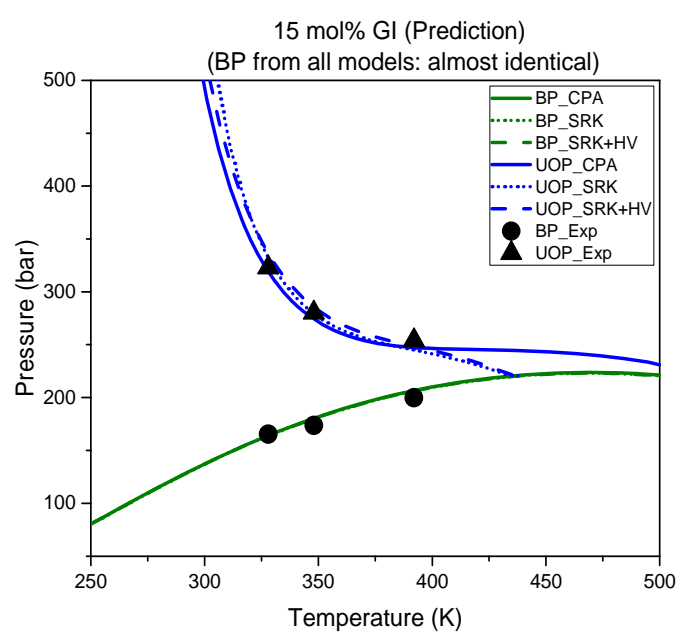

(b)

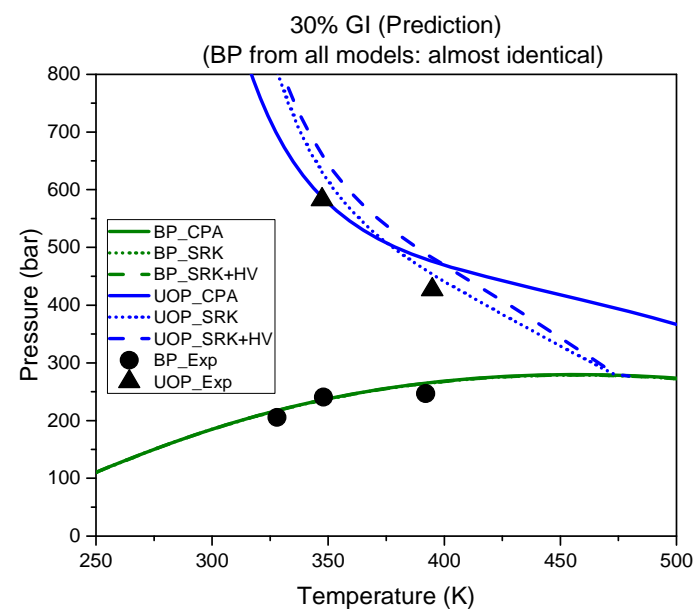

(c)

Fig. 8. Fluid-6: Upper onset and bubble pressure boundaries for reservoir fluid with gas injection of 10 mol\% (Fig. 8a), 15 mol\% (Fig. 8b) and 30 mol\% (Fig. 8c). Symbols represent experimental data from Punnapala et al [31] and lines represent results from all the three models. Asphaltene amount in $\mathbf{C}_{6+}$ fraction is $0.1 \mathrm{~mol} \%$. 


\section{Fluid-1 with splitting of $C_{6 \pm}$ fraction into Nine Heavy Components and Asphaltene}

Generally reservoir fluids are modeled by dividing them into a few pseudo-components, in addition to defined components, in order to accurately predict PVT (Pressure-VolumeTemperature) properties. The modeling approach described above divides the $\mathrm{C}_{6+}$ fraction into two components (heavy component and asphaltene), but here we demonstrate how to extend the modeling approach by dividing the $\mathrm{C}_{6+}$ fraction into multiple heavy components and a single asphaltene component. In this study, the $\mathrm{C}_{6+}$ fraction of Fluid-1 is divided into nine heavy components and asphaltene. Generally, the plus fraction of reservoir fluid is divided into 4-5 pseudo-components but in this work 10 pseudo-components (including asphaltene) are used as a conservative measure. The exponential molar distribution is assumed to divide the $\mathrm{C}_{6+}$ fraction into 80 components which then are lumped into nine heavy components having approximately equal mass fractions. An asphaltene molecular weight of $6165 \mathrm{Da}$, corresponding to $0.1 \mathrm{~mol} \%$ of asphaltene in $\mathrm{C}_{6+}$ fraction, is selected. The critical pressures of all heavy components are multiplied by the same factor in order to match the experimental bubble pressure of Fluid-1. It should be noted that, like bubble pressure, other PVT properties (e.g. density, compressibility, gas to oil ratio) can also be considered during fluid characterization. Values of these PVT properties may depend upon the number of pseudo-components for a given fluid characterization approach. The binary parameters of the nine heavy components with the asphaltene are assumed to be equal and the values are shown in Table 6. Figs 3 and 9 show the upper onset and bubble pressure profiles when one and nine heavy components respectively are considered. These figures show that all three models have the same upper onset and bubble pressure profiles. Table 8 shows the relative deviations in the UOP when one and nine heavy components are considered. The relative deviations for all three models are the same in both cases. In other words, all three models are insensitive to the number of heavy components. 


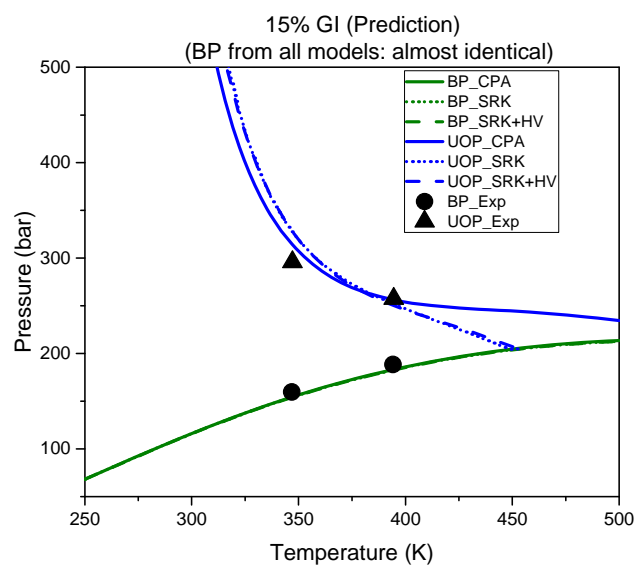

(a)

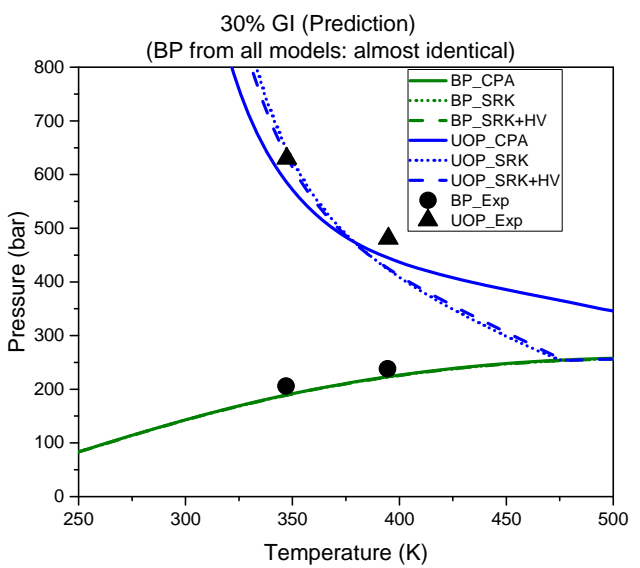

(b)

Fig. 9. Fluid-1 (with $9 \mathrm{HC}$ ): Upper onset and bubble pressure boundaries for reservoir fluid with gas injection of 15 mol\% (Fig. 9a) and 30 mol\% (Fig. 9b). Symbols represent experimental data from Panuganti et al [14] and lines represent results from all the three models. Asphaltene amount in $\mathbf{C}_{6+}$ fraction is $0.1 \mathrm{~mol} \%$. 


\section{Conclusions}

It has been shown in this work that the CPA, SRK and SRK+HV models can successfully predict the gas $\left(\mathrm{CO}_{2}, \mathrm{~N}_{2}\right.$, hydrocarbon) injection effect after fitting the model parameters to experimental data of a single gas injection scenario. The temperature dependent cross association energy, the binary interaction parameters $\left(k_{\mathrm{ij}}\right)$, and the Huron-Vidal parameters between the heavy component and the asphaltene are used as model parameters for the $\mathrm{CPA}, \mathrm{SRK}$ and SRK+HV models respectively. However, the three models give very different predictions outside of the experimental temperature range used in parameters estimation. The CPA model is relatively insensitive to the molar amount of asphaltene in $\mathrm{C}_{6+}$ fraction, whereas the SRK and SRK+HV models are sensitive to the molar amount of asphaltene in $\mathrm{C}_{6+}$ fraction, although the sensitivity is lower for $\mathrm{N}_{2}$ compared to $\mathrm{CO}_{2}$ and hydrocarbon gas injection. Therefore, in order to use the SRK and SRK+HV models, the molar amount of asphaltene needs to be fixed at the same value at which the binary parameters for gasasphaltene and light alkanes-asphaltene pairs are regressed. In this work, we assumed the asphaltene molar amount is $0.1 \mathrm{~mol} \%$ in the $\mathrm{C}_{6+}$ fraction. It would be interesting to do the comparison at different asphaltene molar amounts (e.g. 1 mol\%). The SRK and SRK+HV models abruptly change the lower onset pressure trend and predict the asphaltene precipitation at ambient pressure (possibly due to incorrect convergence) for certain fluids. This abrupt change can be avoided by changing the asphaltene molar amount (generally by increasing it), requiring regression of a new set of binary parameters. Generally, the SRK $+\mathrm{HV}$ model used in this work cannot correlate the data for the upper onset pressures for certain fluids when the asphaltene molar amount used corresponds to an asphaltene molecular weight of $10000 \mathrm{Da}$. Thus the SRK+HV model has no apparent advantages over the SRK model. In contrast to the SRK and SRK+HV models, the CPA model has not encountered any problems, and appears to be more reliable. It has also been shown that a modeling approach can be used in which the $\mathrm{C}_{6+}$ fraction is divided into multiple heavy components and a single asphaltene component. With this approach, the results from all three model are insensitive to the number of heavy components. Therefore, the modeling approach using the CPA EoS can easily be implemented into PVT simulations for reservoir fluids, since it can adequately model such systems using only a few components. Finally, it should be noted that the different modeling approach could improve one model (e.g. SRK) over another (e.g. SRK+HV). 


\section{Acknowledgement}

The authors wish to thank BP International limited (UK), Statoil (Norway) and Petrobras (Brazil) for supporting the work as part of the CHIGP (Chemical in Gas Processing) project. The authors are grateful to Dr. Nikolaos Diamantonis and Dr. Leslie Bolton from BP International Limited (UK) for reviewing this article and providing constructive comments.

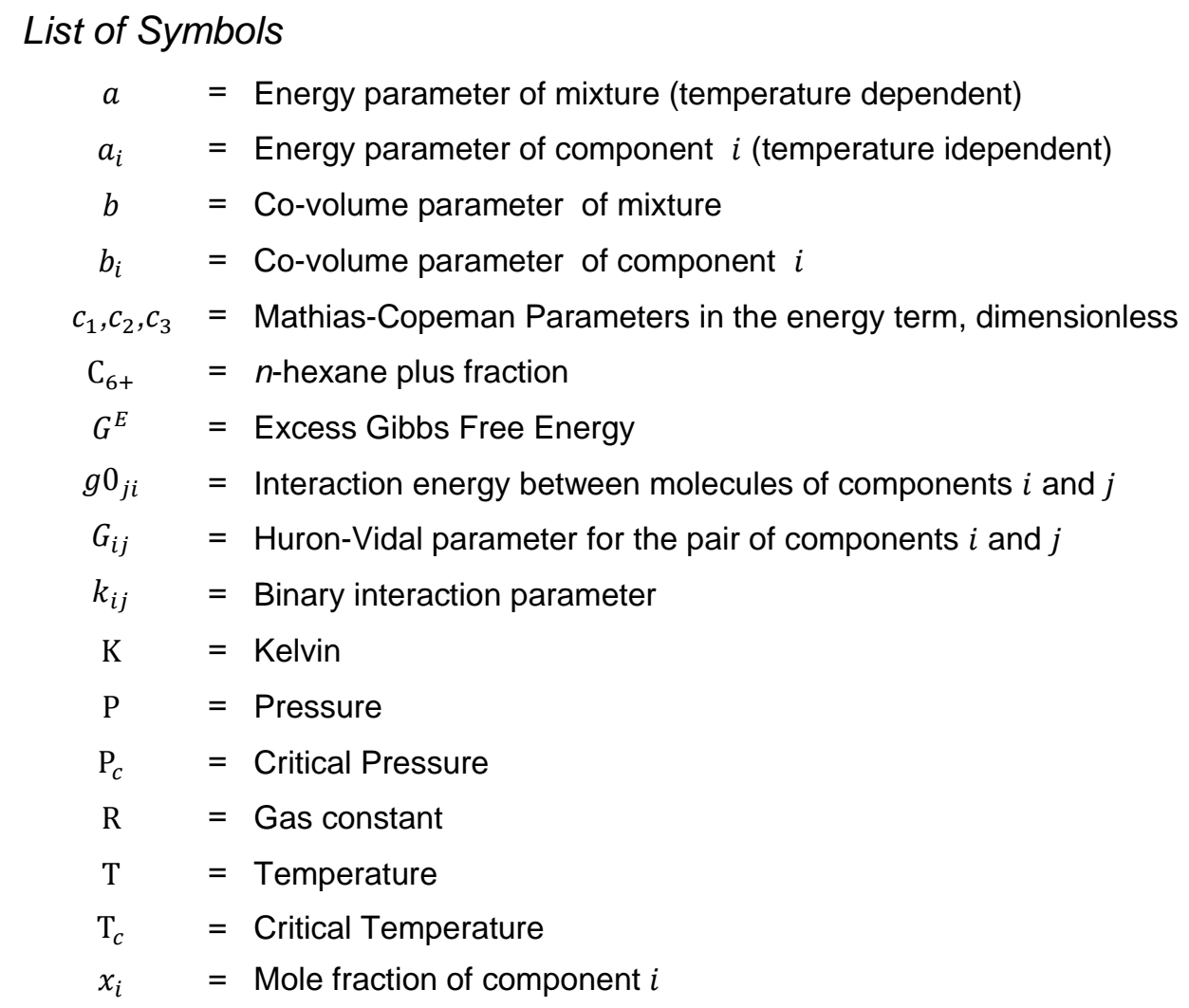

\section{Greek Letter}

$\beta^{A_{i} B_{j}}=$ Association volume between site $A$ of component $i$ and site $B$ of component $j$

$\varepsilon^{A_{i} B_{j}}=$ Association energy between site $A$ of component $i$ and site $B$ of component $j$

$\omega=$ Acentric factor

$\alpha_{i j} \quad=\quad$ Non-randomness factor for the pair of component $i$ and $j$ in Huron-Vidal mixing rule 


\section{List of Abbreviations}

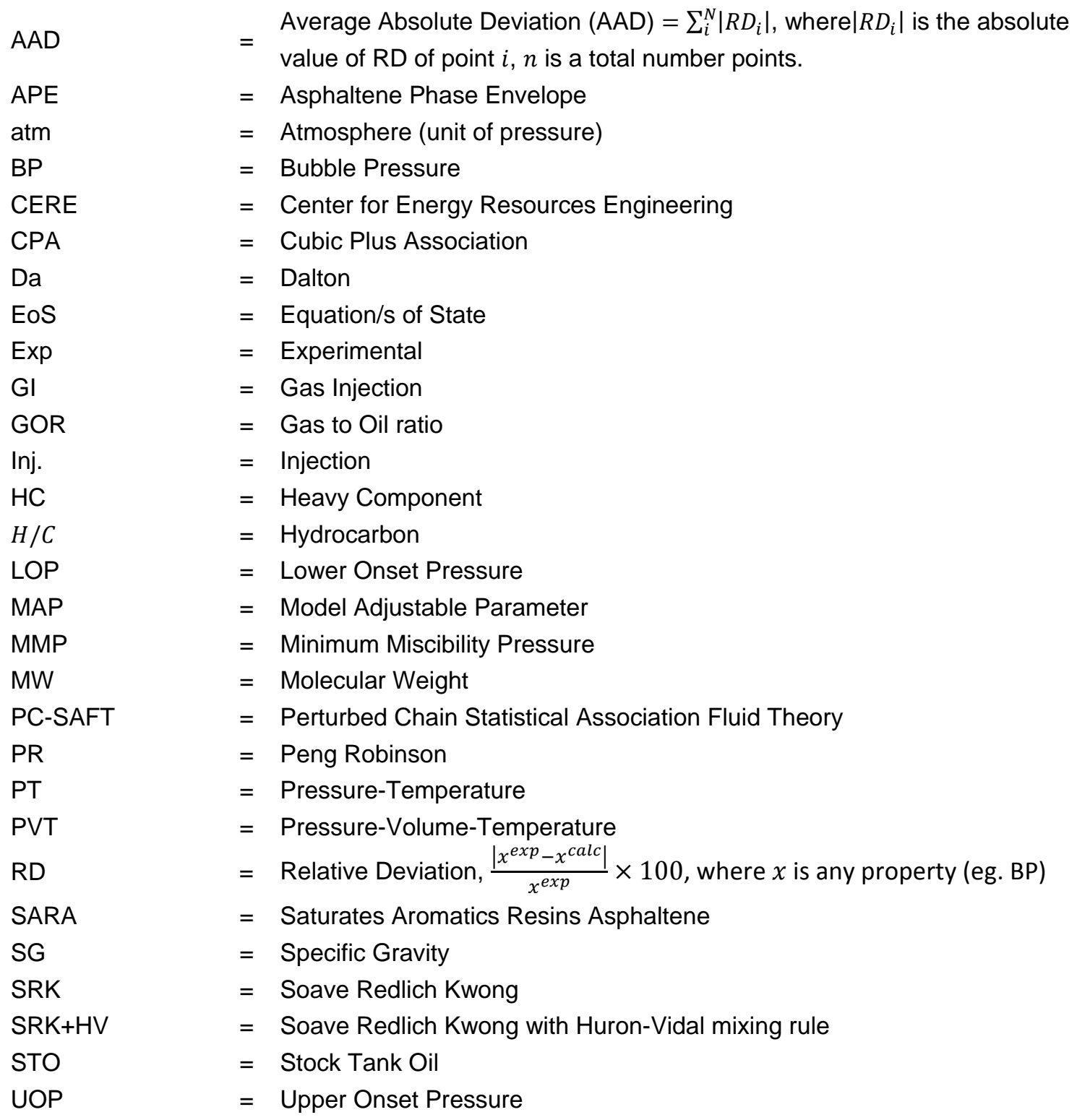




\section{References}

1 J. G. Speight, Petroleum Asphaltenes-Part 1: Asphaltenes, resins and the structure of petroleum, Oil and gas science and technology 59-5 (2004) 467-477.

2 Hirschberg, A., DeJong, L. N. J., Schipper, B. A., and Meijer, J. G. (1984). Influence of temperature and pressure on asphaltene flocculation. Society of Petroleum Engineers Journal, 24(03), 283-293.

3 F. Vargas, M. Garcia-Bermudes, M. Boggara, S. Punnapala, M.I. Abutaqiya, N.T. Mathew, H.Y. Al Asafen, On the Development of an Enhanced Method to Predict Asphaltene Precipitation, In Offshore Technology Conference held in Houston, Texas, USA, 05-08 May-(2014).

4 Pedrosa, N., Szczepanski, R., \& Zhang, X. (2013). Integrated equation of state modelling for flow assurance. Fluid Phase Equilibria, 359, 24-37.

5 Malik, Q. M., \& Islam, M. R. (2000, January). CO2 Injection in the Weyburn field of Canada: optimization of enhanced oil recovery and greenhouse gas storage with horizontal wells. In SPE/DOE improved oil recovery symposium. Society of Petroleum Engineers.

6 Taber, J. J. (1994). A study of technical feasibility for the utilization of CO2 for enhanced oil recovery. The Utilization of Carbon Dioxide from Fossil Fuel Fired Power Stations, 134-204.

7 Stalkup, F. I. (1987, January). Displacement behavior of the condensing/vaporizing gas drive process. In SPE Annual Technical Conference and Exhibition. Society of Petroleum Engineers.

8 Holm, W. L. (1987). Evolution of the carbon dioxide flooding processes. Journal of petroleum technology, 39(11), 1-337.

9 Holm, L. W. (1986). Miscibility and miscible displacement. Journal of Petroleum Technology, 38(08), 817-818.

10 Hoffman, B. T. (2012, January). Comparison of various gases for enhanced recovery from shale oil reservoirs. SPE Improved Oil Recovery Symposium, 14-18 April, Tulsa, Oklahoma, USA.

11 Yan, W., Michelsen, M. L., \& Stenby, E. H. (2011, January). On application of non-cubic EoS to compositional reservoir simulation. In SPE EUROPEC/EAGE Annual Conference and Exhibition, 23-26 May, Vienna, Austria.

12 Jamaluddin, A. K. M., Creek, J., Kabir, C. S., McFadden, J. D., D'Cruz, D., Manakalathil, J., \& Ross, B. (2002). Laboratory techniques to measure thermodynamic asphaltene instability. Journal of Canadian Petroleum Technology, 41(07).

13 Pedersen, K. S., Christensen, P. L., \& Shaikh, J. A. (2014). Phase behavior of petroleum reservoir fluids. CRC Press.

14 Panuganti, S. R., Vargas, F. M., Gonzalez, D. L., Kurup, A. S., \& Chapman, W. G. (2012). PC-SAFT characterization of crude oils and modeling of asphaltene phase behavior. Fuel, 93, 658-669.

15 Hustad, O. S., Jia, N., Pedersen, K. S., Memon, A. I., \& Leekumjorn, S. (2013, September). High pressure data and modeling results for phase behavior and asphaltene onsets of GoM Oil mixed with nitrogen. In SPE Annual Technical Conference and Exhibition, 30 September-2 October, New Orleans, Louisiana, USA.

16 Zhang, X., Pedrosa, N., \& Moorwood, T. (2012). Modeling asphaltene phase behavior: comparison of methods for flow assurance studies. Energy \& Fuels,26(5), 2611-2620.

17 Arya, A., von Solms, N., \& Kontogeorgis, G. M. (2015). Determination of asphaltene onset conditions using the cubic plus association equation of state. Fluid Phase Equilibria, 400, 8-19.

18 Arya, A., von Solms, N., \& Kontogeorgis, G. M. (2015). Investigation of the Gas Injection Effect on Asphaltene Onset Precipitation Using the Cubic-Plus-Association Equation of State. Energy \& Fuels 30(5), 3560-3574.

Page 26 of 31 
19 Arya, A., Liang, X., von Solms, N., \& Kontogeorgis, G. M. (2016). Modeling of Asphaltene Onset Precipitation Conditions with Cubic Plus Association (CPA) and Perturbed Chain Statistical Associating Fluid Theory (PC-SAFT) Equations of State. Energy \& Fuels, 30(8), 6835-6852.

20 Sutherland, J. A Proposed Model of Asphaltene Solution Behavior. Diss. MS thesis, Imperial College, University of London, London, England, 1982.

21 Wang, J. X., \& Buckley, J. S. (2001). A two-component solubility model of the onset of asphaltene flocculation in crude oils. Energy \& Fuels, 15(5), 1004-1012.

22 Acevedo, S., Castro, A., Vásquez, E., Marcano, F., \& Ranaudo, M. A. (2010). Investigation of physical chemistry properties of asphaltenes using solubility parameters of asphaltenes and their fractions $A 1$ and A2. Energy \& Fuels, 24(11), 5921-5933.

23 Sirota, E. B. (2005). Physical structure of asphaltenes. Energy \& fuels, 19(4), 1290-1296.

24 Kesler, M. G., \& Lee, B. I. (1976). Improve prediction of enthalpy of fractions.Hydrocarbon processing, 55(3), 153-158.

25 G.M. Kontogeorgis, G.K. Folas, Thermodynamic models for industrial applications: from classical and advanced mixing rules to association theories. John Wiley \& Sons (2009).

26 Soave, G. (1972). Equilibrium constants from a modified Redlich-Kwong equation of state. Chemical Engineering Science, 27(6), 1197-1203.

27 Huron, M. J., \& Vidal, J. (1979). New mixing rules in simple equations of state for representing vapourliquid equilibria of strongly non-ideal mixtures. Fluid Phase Equilibria, 3(4), 255-271.

28 Chueh, P. L., Prausnitz, J. M., \& Knapp, H. (1982). Vapor-Liquid Equilibria for Mixtures of Low Boiling Substances. In Chem. Data Series (Vol. 6). DECHEMA Frankfurt/Main.

29 Rodgers, R. P., \& Marshall, A. G. (2007). Petroleomics: Advanced characterization of petroleumderived materials by Fourier transform ion cyclotron resonance mass spectrometry (FT-ICR MS). In Asphaltenes, Heavy Oils, and Petroleomics (pp. 63-93). Springer New York.

30 Gonzalez, D. L., Mahmoodaghdam, E., Lim, F. H., \& Joshi, N. B. (2012, January). Effects of Gas Additions to Deepwater Gulf of Mexico Reservoir Oil: Experimental Investigation of Asphaltene Precipitation and Deposition. In SPE Annual Technical Conference and Exhibition, 8-10 October, San Antonio, Texas, USA.

31 Punnapala, S., \& Vargas, F. M. (2013). Revisiting the PC-SAFT characterization procedure for an improved asphaltene precipitation prediction.Fuel, 108, 417-429.

32 Jamaluddin, A. K. M., Joshi, N., Iwere, F., \& Gurpinar, O. (2002, January). An investigation of asphaltene instability under nitrogen injection. In SPE International Petroleum Conference and Exhibition in Mexico, 10-12 February, Villahermosa, Mexico.

33 Memon, A. I., Qassim, B., Al-ajmi, M. F., Tharanivasan, A. K., Gao, J., Ratulowski, J., ... \& Khan, R. A. (2012, January). Miscible Gas Injection and Asphaltene Flow Assurance Fluid Characterization: A Laboratory Case Study for Black Oil Reservoir. In SPE EOR Conference at Oil and Gas West Asia, 1618 April, Muscat, Oman.

34 http://www.calsep.com/ (Date: $12^{\text {th }}$ Dec 2016)

35 Nasrifar, K., \& Moshfeghian, M. (1998). A saturated liquid density equation in conjunction with the Predictive-Soave-Redlich-Kwong equation of state for pure refrigerants and LNG multicomponent systems. Fluid phase equilibria, 153(2), 231-242. 


\section{Appendix-A}

Table A.1 shows the pure component parameters used in this work for all three models. Table A.2 shows the calculated properties and mol\% of heavy component/s for all fluids studied in this work. All calculated properties of the heavy component are the same for all three models as shown in Table A.2. Tables A.3 to A.9 show the relative deviations in upper onset pressure at experimental temperatures considering different molecular weights.

Table A.1

Pure Component Parameters used for the CPA, SRK and SRK-HV equations of state.

\begin{tabular}{|c|c|c|c|c|c|c|c|}
\hline \multirow{3}{*}{ Component } & \multirow{3}{*}{$\begin{array}{c}T_{C} \\
\mathrm{~K}\end{array}$} & \multirow{2}{*}{$P_{C}$} & \multicolumn{5}{|c|}{ Mathias-Copeman Parameters } \\
\hline & & & $\omega$ & $c_{1}$ & $c_{2}$ & $c_{3}$ & Reference \\
\hline & & bar & - & - & - & - & \\
\hline $\mathrm{N}_{2}$ & 126.2 & 34.00 & 0.0377 & 0.5867 & -0.4459 & 0.8926 & [35] \\
\hline $\mathrm{CO}_{2}$ & 304.2 & 73.83 & 0.2236 & 0.8679 & -0.7135 & 2.6563 & [35] \\
\hline $\mathrm{H}_{2} \mathrm{~S}$ & 373.5 & 89.63 & 0.0942 & 0.6267 & 0 & 0 & [35] \\
\hline methane & 190.6 & 45.99 & 0.0115 & 0.5857 & -0.7206 & 1.2899 & [35] \\
\hline ethane & 305.3 & 48.72 & 0.0995 & 0.7178 & -0.7644 & 1.6396 & [35] \\
\hline propane & 369.8 & 42.48 & 0.1523 & 0.7863 & -0.7459 & 1.8454 & [35] \\
\hline$i$-butane & 408.1 & 36.48 & 0.1808 & 0.8284 & -0.8285 & 2.3201 & [35] \\
\hline$n$-butane & 425.2 & 37.96 & 0.2002 & 0.8787 & -0.9399 & 2.2666 & [35] \\
\hline$i$-pentane & 460.4 & 33.81 & 0.2275 & 0.8290 & 0 & 0 & [35] \\
\hline$n$-pentane & 469.7 & 33.70 & 0.2515 & 0.8647 & 0 & 0 & [35] \\
\hline Heavy Comp & Table A.2 & Table A.2 & Table A.2 & Table A.2 & 0 & 0 & Table A.2 \\
\hline asphaltene $^{\mathrm{A}}$ & 1040.1 & 15.44 & 1.535 & 2.4814 & 0 & 0 & [17-19] \\
\hline
\end{tabular}

A For the CPA model, asphaltene reduced self-association energy and volume are $3000 \mathrm{~K}$ and 0.05 respectively.

Table A.2

Properties and Composition of Heavy Component/s for all fluids studied in this work for a given asphaltene MW. These values are the same for all three models.

\begin{tabular}{cccccccc}
\hline Fluid & $\begin{array}{c}\text { Asp MW } \\
\text { Da }\end{array}$ & Component & $\begin{array}{c}\mathrm{HC} \\
\text { Composition } \\
\text { mol\% }\end{array}$ & $\begin{array}{c}\text { Asp } \\
\text { Composition } \\
\text { mol\% }\end{array}$ & $\begin{array}{c}T_{C} \\
\mathrm{~K}\end{array}$ & $\begin{array}{c}\omega \\
\text { bar }\end{array}$ \\
\hline Fluid-1 & 6165 & $\mathrm{HC}-1$ & 36.567 & 0.037 & 735.6 & 0.7407 & 14.33 \\
Fluid-2 & 38500 & $\mathrm{HC}-1$ & 47.492 & 0.048 & 775.2 & 0.6428 & 18.28 \\
Fluid-3 & 372 & $\mathrm{HC}-1$ & 24.386 & 0.025 & 753.0 & 0.7491 & 17.34 \\
Fluid-4 & 3450 & $\mathrm{HC}-1$ & 32.960 & 0.033 & 775.9 & 0.7914 & 16.25 \\
Fluid-5 & 3100 & $\mathrm{HC}-1$ & 38.112 & 0.038 & 760.1 & 0.7331 & 16.22 \\
Fluid-6 & 330 & $\mathrm{HC}-1$ & 38.514 & 0.039 & 726.2 & 0.7181 & 16.55 \\
& & $\mathrm{HC}-1$ & 10.831 & & 533.6 & 0.4843 & 22.31 \\
& & $\mathrm{HC}-2$ & 7.625 & & 612.7 & 0.6388 & 15.62 \\
Fluid-1 & & $\mathrm{HC}-3$ & 5.369 & & 673.6 & 0.7835 & 13.22 \\
(with 9 HC) & 6165 & $\mathrm{HC}-4$ & 3.780 & & 725.5 & 0.9160 & 12.13 \\
& & $\mathrm{HC}-5$ & 2.661 & 0.040 & 771.9 & 1.0345 & 11.57 \\
& & $\mathrm{HC}-6$ & 2.248 & & 819.4 & 1.1479 & 11.26 \\
& & $\mathrm{HC}-7$ & 1.874 & & 877.2 & 1.2636 & 11.11 \\
& & $\mathrm{HC}-8$ & 1.291 & & 952.1 & 1.3539 & 11.12 \\
\hline
\end{tabular}


Table A.3

Fluid-1: Relative Deviation (RD) in calculated Upper Onset Pressure (UOP) with respect to experimental data for different amounts of gas injection and considering different asphaltene molecular weights.

\begin{tabular}{|c|c|c|c|c|c|c|c|c|c|c|c|c|c|c|c|c|c|c|c|c|}
\hline \multirow{3}{*}{$\begin{array}{l}\text { Asp } \\
\text { MW } \\
(\mathrm{Da})\end{array}$} & \multicolumn{5}{|c|}{$H / C$ Gas Injection $=0 \mathrm{~mol} \%$} & \multicolumn{5}{|c|}{$H / C$ Gas Injection=5 mol\% } & \multicolumn{5}{|c|}{$H / C$ Gas Injection=15 mol\% } & \multicolumn{5}{|c|}{$H / C$ Gas Injection=30 mol\% } \\
\hline & \multirow{2}{*}{$\begin{array}{l}\text { Exp } \\
\text { Temp } \\
\text { (K) }\end{array}$} & \multirow{2}{*}{$\begin{array}{l}\text { Exp } \\
\text { UOP } \\
\text { (bar) }\end{array}$} & \multicolumn{3}{|c|}{$\begin{array}{c}\text { RD in calculated } \\
\text { UOP } \\
(\%) \\
\end{array}$} & \multirow{2}{*}{$\begin{array}{l}\text { Exp } \\
\text { UOP } \\
\text { (bar) }\end{array}$} & \multirow{2}{*}{$\begin{array}{l}\text { Exp } \\
\text { UOP } \\
\text { (bar) }\end{array}$} & \multicolumn{3}{|c|}{$\begin{array}{c}\text { RD in calculated } \\
\text { UOP } \\
(\%) \\
\end{array}$} & \multirow{2}{*}{$\begin{array}{l}\text { Exp } \\
\text { Temp } \\
(\mathrm{K})\end{array}$} & \multirow{2}{*}{$\begin{array}{l}\text { Exp } \\
\text { UOP } \\
\text { (bar) }\end{array}$} & \multicolumn{3}{|c|}{$\begin{array}{c}\text { RD in calculated } \\
\text { UOP } \\
(\%)\end{array}$} & \multirow[t]{2}{*}{$\begin{array}{l}\text { Exp } \\
\text { Temp } \\
(\mathrm{K})\end{array}$} & \multirow{2}{*}{$\begin{array}{l}\text { Exp } \\
\text { UOP } \\
\text { (bar) }\end{array}$} & \multicolumn{3}{|c|}{$\begin{array}{c}\text { RD in calculated } \\
\text { UOP } \\
(\%)\end{array}$} \\
\hline & & & CPA & SRK & $\begin{array}{c}\text { SRK } \\
+ \\
\text { HV }\end{array}$ & & & CPA & SRK & $\begin{array}{c}\text { SRK } \\
+ \\
\mathrm{HV}\end{array}$ & & & CPA & SRK & $\begin{array}{c}\text { SRK } \\
+ \\
\mathrm{HV}\end{array}$ & & & CPA & SRK & $\begin{array}{c}\text { SRK } \\
+ \\
\mathrm{HV}\end{array}$ \\
\hline \multirow{4}{*}{6165} & 328 & 107 & -69 & -61 & -60 & 328 & 238 & -1 & 0 & -1 & & & & & & & & & & \\
\hline & 347 & 126 & -14 & -12 & -12 & 347 & 193 & 0 & -1 & -1 & 347 & 296 & -7 & -11 & -12 & 347 & 630 & 6 & -3 & -1 \\
\hline & 394 & 152 & 2 & 3 & 3 & 394 & 168 & 0 & 0 & 2 & 394 & 257 & -1 & 2 & 3 & 394 & 481 & 5 & 12 & 13 \\
\hline & & AAD & 28 & 25 & \multicolumn{2}{|l|}{25} & & 0 & 0 & \multicolumn{2}{|l|}{1} & & 4 & 6 & \multicolumn{2}{|l|}{7} & & 5 & 7 & 7 \\
\hline \multirow{4}{*}{750} & 328 & 107 & -69 & -57 & -56 & 328 & 238 & 0 & -1 & 1 & & & & & & & & & & \\
\hline & 347 & 126 & -15 & -8 & -9 & 347 & 193 & 0 & 0 & -1 & 347 & 296 & -7 & -16 & -15 & 347 & 630 & 6 & -16 & -9 \\
\hline & 394 & 152 & 2 & 2 & 1 & 394 & 168 & 0 & 0 & 1 & 394 & 257 & -1 & -4 & -4 & 394 & 481 & 4 & -2 & -2 \\
\hline & & AAD & 28 & 22 & \multicolumn{2}{|l|}{22} & & 0 & 0 & \multicolumn{2}{|l|}{1} & & 4 & 10 & \multicolumn{2}{|l|}{10} & & 5 & 9 & 6 \\
\hline \multirow{4}{*}{10000} & 328 & 107 & -69 & -63 & -63 & 328 & 238 & 0 & -1 & 0 & & & & & & & & & & \\
\hline & 347 & 126 & -15 & -13 & -15 & 347 & 193 & -1 & 0 & -1 & 347 & 296 & -7 & -9 & -8 & 347 & 630 & 6 & 2 & 7 \\
\hline & 394 & 152 & 3 & 3 & 3 & 394 & 168 & -1 & 0 & 1 & 394 & 257 & -1 & 4 & 8 & 394 & 481 & 5 & 16 & 23 \\
\hline & & AAD & 29 & 26 & 27 & & & 1 & 0 & 1 & & & 4 & 7 & 8 & & & 5 & 9 & 15 \\
\hline
\end{tabular}

Table A.4

Fluid-2: Relative Deviation (RD) in calculated Upper Onset Pressure (UOP) with respect to experimental data for different amounts of gas injection and considering different asphaltene molecular weights.

\begin{tabular}{|c|c|c|c|c|c|c|c|c|c|c|c|c|c|c|c|c|c|c|c|c|}
\hline \multirow{3}{*}{$\begin{array}{l}\text { Asp } \\
\text { MW } \\
\text { (Da) }\end{array}$} & \multicolumn{5}{|c|}{ Gas Injection=0 mol\% } & \multicolumn{5}{|c|}{$N_{2}$ Injection=10 mol\% } & \multicolumn{5}{|c|}{$\mathrm{CO}_{2}$ Injection $=10 \mathrm{~mol} \%$} & \multicolumn{5}{|c|}{ Methane Injection=10 mol\% } \\
\hline & \multirow{2}{*}{$\begin{array}{c}\text { Exp } \\
\text { Temp } \\
(\mathrm{K})\end{array}$} & \multirow{2}{*}{$\begin{array}{l}\text { Exp } \\
\text { UOP } \\
\text { (bar) }\end{array}$} & \multicolumn{3}{|c|}{$\begin{array}{c}\text { RD in calculated } \\
\text { UOP } \\
(\%)\end{array}$} & \multirow{2}{*}{$\begin{array}{l}\text { Exp } \\
\text { Temp } \\
(\mathrm{K})\end{array}$} & \multirow{2}{*}{$\begin{array}{l}\text { Exp } \\
\text { UOP } \\
\text { (bar) }\end{array}$} & \multicolumn{3}{|c|}{$\begin{array}{c}\text { RD in calculated } \\
\text { UOP } \\
(\%)\end{array}$} & \multirow{2}{*}{$\begin{array}{c}\text { Exp } \\
\text { Temp } \\
(\mathrm{K})\end{array}$} & \multirow{2}{*}{$\begin{array}{l}\text { Exp } \\
\text { UOP } \\
\text { (bar) }\end{array}$} & \multicolumn{3}{|c|}{$\begin{array}{c}\text { RD in calculated } \\
\text { UOP } \\
(\%)\end{array}$} & \multirow{2}{*}{$\begin{array}{l}\text { Exp } \\
\text { Temp } \\
\text { (K) }\end{array}$} & \multirow{2}{*}{$\begin{array}{l}\text { Exp } \\
\text { UOP } \\
\text { (bar) }\end{array}$} & \multicolumn{3}{|c|}{$\begin{array}{c}\text { RD in calculated } \\
\text { UOP } \\
(\%)\end{array}$} \\
\hline & & & CPA & SRK & $\begin{array}{l}\text { SRK } \\
+ \\
\mathrm{HV}\end{array}$ & & & CPA & SRK & $\begin{array}{c}\text { SRK } \\
+ \\
\mathrm{HV}\end{array}$ & & & CPA & SRK & $\begin{array}{c}\text { SRK } \\
+ \\
\text { HV }\end{array}$ & & & CPA & SRK & $\begin{array}{c}\text { SRK } \\
+ \\
H V\end{array}$ \\
\hline \multirow{7}{*}{38500} & 371 & 317 & 0 & -1 & 0 & 371 & 669 & -1 & -4 & -9 & 371 & 428 & -3 & 6 & 7 & 371 & 566 & 7 & 5 & -27 \\
\hline & 339 & 348 & 0 & 0 & 0 & 339 & 841 & 2 & -2 & -4 & 339 & 490 & 1 & 2 & 1 & 339 & 724 & 16 & 10 & -26 \\
\hline & & & & & & 325 & 931 & -3 & -7 & -11 & & & & & & & & & & \\
\hline & 311 & 462 & -2 & -1 & -6 & 311 & 1352 & 10 & 7 & 5 & 311 & 676 & 6 & 0 & -3 & 311 & 897 & 8 & -6 & -67 \\
\hline & 304 & 552 & 2 & 3 & 1 & & & & & & 304 & 759 & 6 & -3 & -3 & & & & & \\
\hline & 300 & 593 & -1 & -1 & 0 & & & & & & & & & & & & & & & \\
\hline & & AAD & 1 & 1 & 1 & & & 3 & 3 & 4 & & & 4 & 3 & 3 & & & 10 & 7 & 40 \\
\hline \multirow{7}{*}{750} & 371 & 317 & 0 & 0 & 0 & 371 & 669 & 2 & 1 & -9 & 371 & 428 & -1 & -10 & -33 & 371 & 566 & 9 & 0 & -5 \\
\hline & 339 & 348 & -1 & 0 & 0 & 339 & 841 & 5 & 5 & -1 & 339 & 490 & 4 & -10 & -32 & 339 & 724 & 19 & 8 & 3 \\
\hline & & & & & & 325 & 931 & 0 & -1 & -8 & & & & & & & & & & \\
\hline & 311 & 462 & -4 & -4 & -7 & 311 & 1352 & 14 & 13 & 8 & 311 & 676 & 9 & -10 & -36 & 311 & 897 & 11 & -6 & -17 \\
\hline & 304 & 552 & 2 & 2 & 0 & & & & & & 304 & 759 & 10 & -11 & -35 & & & & & \\
\hline & 300 & 593 & -1 & -1 & -1 & & & & & & & & & & & & & & & \\
\hline & & AAD & 1 & 1 & 2 & & & 5 & 5 & 4 & & & 6 & 10 & 34 & & & 13 & 5 & 9 \\
\hline
\end{tabular}


Table A.5

Fluid-3: Relative Deviation (RD) in calculated Upper Onset Pressure (UOP) with respect to experimental data for different amounts of $\mathrm{CO}_{2}$ injection and considering different asphaltene molecular weights.

\begin{tabular}{|c|c|c|c|c|c|c|c|c|c|c|}
\hline \multirow{3}{*}{$\begin{array}{l}\text { Asp } \\
\mathrm{MW} \\
\text { (Da) }\end{array}$} & \multicolumn{5}{|c|}{$\mathrm{CO}_{2}$ Gas Injection=20 mol\% } & \multicolumn{5}{|c|}{$\boldsymbol{C O}_{2}$ Gas Injection=30 mol\% } \\
\hline & \multirow{2}{*}{$\begin{array}{c}\text { Exp } \\
\text { Temp } \\
\text { (K) }\end{array}$} & \multirow{2}{*}{$\begin{array}{l}\text { Exp } \\
\text { UOP } \\
\text { (bar) }\end{array}$} & \multicolumn{3}{|c|}{$\begin{array}{c}\mathrm{RD} \text { in calculated UOP } \\
(\%)\end{array}$} & \multirow{2}{*}{$\begin{array}{c}\text { Exp } \\
\text { Temp } \\
\text { (K) }\end{array}$} & \multirow{2}{*}{$\begin{array}{l}\text { Exp } \\
\text { UOP } \\
\text { (bar) }\end{array}$} & \multicolumn{3}{|c|}{$\begin{array}{c}\mathrm{RD} \text { in calculated UOP } \\
(\%)\end{array}$} \\
\hline & & & CPA & SRK & $\begin{array}{c}\text { SRK } \\
+ \\
\mathrm{HV}\end{array}$ & & & CPA & SRK & $\begin{array}{c}\text { SRK } \\
+ \\
\text { HV }\end{array}$ \\
\hline \multirow{3}{*}{372} & 355 & 387 & -1 & 0 & 0 & 355 & 490 & -4 & -4 & -6 \\
\hline & 394 & 363 & -1 & 0 & 0 & 394 & 444 & -5 & 1 & -5 \\
\hline & & AAD & 1 & 0 & 0 & & & 4 & 2 & 6 \\
\hline \multirow{3}{*}{10000} & 355 & 387 & -1 & 0 & $N A^{a}$ & 355 & 490 & -3 & 17 & $N A^{a}$ \\
\hline & 394 & 363 & 0 & 0 & $N A^{a}$ & 394 & 444 & -3 & 23 & $N A^{a}$ \\
\hline & & AAD & 0 & 0 & $N A^{a}$ & & & 3 & 20 & $N A^{a}$ \\
\hline
\end{tabular}

${ }^{a} \mathrm{SRK}+\mathrm{HV}$ model parameters could not be calculated for this case.

Table A.6

Fluid-4: Relative Deviation (RD) in calculated Upper Onset Pressure (UOP) with respect to experimental data for different amounts of $\boldsymbol{N}_{2}$ injection and considering different asphaltene molecular weights.

\begin{tabular}{|c|c|c|c|c|c|c|c|c|c|c|}
\hline \multirow{3}{*}{$\begin{array}{l}\text { Asp } \\
\text { MW } \\
(\mathrm{Da})\end{array}$} & \multicolumn{5}{|c|}{ Gas Injection=0 mol\% } & \multicolumn{5}{|c|}{$\boldsymbol{N}_{2}$ Injection @ $419 \mathrm{~K}$} \\
\hline & \multirow{2}{*}{$\begin{array}{l}\text { Exp } \\
\text { Temp } \\
\text { (K) }\end{array}$} & \multirow{2}{*}{$\begin{array}{l}\text { Exp } \\
\text { UOP } \\
\text { (bar) }\end{array}$} & \multicolumn{3}{|c|}{$\begin{array}{l}\text { RD in calculated UOP } \\
(\%)\end{array}$} & \multirow{2}{*}{$\begin{array}{c}\text { Exp } \\
\text { gas Inj. } \\
\text { (mol\%) }\end{array}$} & \multirow{2}{*}{$\begin{array}{l}\text { Exp } \\
\text { UOP } \\
\text { (bar) }\end{array}$} & \multicolumn{3}{|c|}{$\begin{array}{l}\mathrm{RD} \text { in calculated UOP } \\
(\%)\end{array}$} \\
\hline & & & CPA & SRK & $\begin{array}{c}\text { SRK } \\
+ \\
\mathrm{HV} \\
\end{array}$ & & & CPA & SRK & $\begin{array}{c}\text { SRK } \\
+ \\
\mathrm{HV}\end{array}$ \\
\hline \multirow{5}{*}{3450} & 361 & 373 & $\begin{array}{l}-1 \\
\end{array}$ & 0 & -2 & 5 & 379 & 7 & 8 & 8 \\
\hline & 383 & 280 & 4 & 5 & 3 & 10 & 532 & 12 & 13 & 14 \\
\hline & 400 & 251 & 0 & 0 & -3 & 20 & 804 & 0 & 0 & 1 \\
\hline & 422 & 262 & 0 & 0 & 1 & & & & & \\
\hline & & AAD & 1 & 1 & 2 & & & 6 & 7 & 8 \\
\hline \multirow{5}{*}{750} & 361 & 373 & 0 & 0 & 0 & 5 & 379 & 8 & 7 & 3 \\
\hline & 383 & 280 & 4 & 4 & 1 & 10 & 532 & 13 & 12 & 3 \\
\hline & 400 & 251 & 0 & 0 & -2 & 20 & 804 & 2 & -1 & -27 \\
\hline & 422 & 262 & 0 & 0 & 0 & & & & & \\
\hline & & AAD & 1 & 1 & 1 & & & 8 & 7 & 11 \\
\hline \multirow{5}{*}{10000} & 361 & 373 & -1 & -1 & $N A^{a}$ & 5 & 379 & 6 & 8 & $N A^{a}$ \\
\hline & 383 & 280 & 5 & 5 & $N A^{a}$ & 10 & 532 & 11 & 13 & $N A^{a}$ \\
\hline & 400 & 251 & -1 & 0 & $N A^{a}$ & 20 & 804 & -2 & 1 & $N A^{a}$ \\
\hline & 422 & 262 & 0 & 0 & $N A^{a}$ & & & & & \\
\hline & & AAD & 2 & 1 & & & & 7 & 7 & \\
\hline
\end{tabular}

aSRK+HV model parameters could not be calculated for this case. 
Table A.7

Fluid-5: Relative Deviation (RD) in calculated Upper Onset Pressure (UOP) with respect to experimental data for different amounts of $\mathrm{CO}_{2}$ injection and considering different asphaltene molecular weights.

\begin{tabular}{|c|c|c|c|c|c|c|c|c|c|c|}
\hline \multirow{3}{*}{$\begin{array}{l}\text { Asp } \\
\text { MW } \\
\text { (Da) }\end{array}$} & \multicolumn{5}{|c|}{ Gas Injection=0 mol\% } & \multicolumn{5}{|c|}{$\mathrm{CO}_{2}$ rich gas Injection @363 K } \\
\hline & \multirow{2}{*}{$\begin{array}{l}\text { Exp } \\
\text { Temp } \\
(\mathrm{K})\end{array}$} & \multirow{2}{*}{$\begin{array}{l}\text { Exp } \\
\text { UOP } \\
\text { (bar) }\end{array}$} & \multicolumn{3}{|c|}{$\begin{array}{l}\text { RD in calculated UOP } \\
(\%)\end{array}$} & \multirow{2}{*}{$\begin{array}{c}\text { Exp } \\
\text { gas Inj. } \\
\text { (mol\%) }\end{array}$} & \multirow{2}{*}{$\begin{array}{l}\text { Exp } \\
\text { UOP } \\
\text { (bar) }\end{array}$} & \multicolumn{3}{|c|}{$\begin{array}{l}\text { RD in calculated UOP } \\
(\%)\end{array}$} \\
\hline & & & CPA & SRK & $\begin{array}{c}\text { SRK } \\
+ \\
\text { HV }\end{array}$ & & & CPA & SRK & $\begin{array}{c}\text { SRK } \\
+ \\
\mathrm{HV}\end{array}$ \\
\hline \multirow{4}{*}{3100} & 336 & 302 & -1 & -1 & 0 & 10 & 247 & -1 & -1 & 1 \\
\hline & 350 & 189 & 0 & -1 & 1 & 15 & 323 & 4 & 5 & 4 \\
\hline & & & & & & 25 & 440 & -5 & -1 & -8 \\
\hline & & AAD & 1 & 1 & 0 & & & 3 & 3 & 4 \\
\hline \multirow{4}{*}{750} & 336 & 302 & -1 & -1 & 0 & 10 & 247 & 0 & -2 & 1 \\
\hline & 350 & 189 & -1 & 0 & 1 & 15 & 323 & 5 & 1 & -2 \\
\hline & & & & & & 25 & 440 & -4 & -15 & -28 \\
\hline & & AAD & 1 & 0 & 0 & & & 3 & 6 & 10 \\
\hline \multirow{4}{*}{10000} & 336 & 302 & -1 & -1 & $N A^{a}$ & 10 & 247 & -1 & -1 & $\mathrm{NA}^{\mathrm{a}}$ \\
\hline & 350 & 189 & 0 & 0 & $N A^{a}$ & 15 & 323 & 5 & 10 & $N A^{a}$ \\
\hline & & & & & & 25 & 440 & -4 & 12 & $N A^{a}$ \\
\hline & & AAD & 1 & 1 & $\mathrm{NA}^{\mathrm{a}}$ & & & 3 & 8 & $N A^{a}$ \\
\hline
\end{tabular}

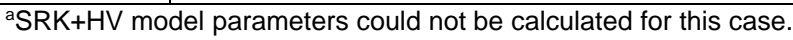

Table A.8

Fluid-6: Relative Deviation (RD) in calculated Upper Onset Pressure (UOP) with respect to experimental data for different amounts of $\mathrm{H} / \mathrm{C}$ gas injection and considering different asphaltene molecular weights.

\begin{tabular}{|c|c|c|c|c|c|c|c|c|c|c|c|c|c|c|c|}
\hline \multirow{3}{*}{$\begin{array}{l}\text { Asp } \\
\text { MW } \\
(\mathrm{Da})\end{array}$} & \multicolumn{5}{|c|}{$H / C$ Gas Injection=10 mol\% } & \multicolumn{5}{|c|}{$\mathrm{H} / \mathrm{C}$ Gas Injection=15 mol\% } & \multicolumn{5}{|c|}{$\mathrm{H} / \mathrm{C}$ Gas Injection=30 $\mathrm{mol} \%$} \\
\hline & \multirow{2}{*}{$\begin{array}{l}\text { Exp } \\
\text { Temp } \\
(\mathrm{K})\end{array}$} & \multirow{2}{*}{$\begin{array}{l}\text { Exp } \\
\text { UOP } \\
\text { (bar) }\end{array}$} & \multicolumn{3}{|c|}{$\begin{array}{l}\text { RD in calculated UOP } \\
(\%)\end{array}$} & \multirow{2}{*}{$\begin{array}{l}\text { Exp } \\
\text { Temp } \\
(\mathrm{K})\end{array}$} & \multirow{2}{*}{$\begin{array}{l}\text { Exp } \\
\text { UOP } \\
\text { (bar) }\end{array}$} & \multicolumn{3}{|c|}{$\begin{array}{l}\text { RD in calculated UOP } \\
(\%)\end{array}$} & \multirow{2}{*}{$\begin{array}{l}\text { Exp } \\
\text { Temp } \\
(\mathrm{K})\end{array}$} & \multirow{2}{*}{$\begin{array}{l}\text { Exp } \\
\text { UOP } \\
\text { (bar) }\end{array}$} & \multicolumn{3}{|c|}{$\begin{array}{l}\text { RD in calculated UOP } \\
(\%)\end{array}$} \\
\hline & & & CPA & SRK & $\begin{array}{c}\text { SRK } \\
+ \\
\text { HV }\end{array}$ & & & CPA & SRK & $\begin{array}{c}\text { SRK } \\
+ \\
\mathrm{HV}\end{array}$ & & & CPA & SRK & $\begin{array}{c}\text { SRK } \\
+ \\
\mathrm{HV} \\
\end{array}$ \\
\hline \multirow{4}{*}{330} & 328 & 233 & -1 & -1 & 0 & 328 & 323 & 1 & -3 & -4 & & & & & \\
\hline & 348 & 203 & 0 & 0 & 0 & 348 & 280 & 2 & 0 & -2 & 348 & 583 & 0 & -8 & -13 \\
\hline & 392 & 190 & -1 & -1 & 0 & 392 & 254 & 3 & 4 & 2 & 392 & 427 & -12 & -8 & -15 \\
\hline & & & 1 & 1 & 0 & & & 2 & 2 & 3 & & & 4 & 5 & 9 \\
\hline \multirow{4}{*}{10000} & 328 & 233 & -1 & 0 & $\mathrm{NA}^{\mathrm{a}}$ & 328 & 323 & 2 & 5 & $\mathrm{NA}^{\mathrm{a}}$ & & & & & \\
\hline & 348 & 203 & 0 & 0 & $N A^{a}$ & 348 & 280 & 3 & 8 & $N A^{a}$ & 348 & 583 & 1 & 19 & $N A^{a}$ \\
\hline & 392 & 190 & -1 & 0 & $N^{a}{ }^{a}$ & 392 & 254 & 3 & 14 & $N A^{a}$ & 392 & 427 & -11 & 25 & $N A^{a}$ \\
\hline & & AAD & 1 & 0 & $N^{a}{ }^{a}$ & & & 2 & 9 & $N A^{a}$ & & & 4 & 15 & $\mathrm{NA}^{\mathrm{a}}$ \\
\hline
\end{tabular}

${ }^{a} \mathrm{SRK}+\mathrm{HV}$ model parameters could not be calculated for this case.

Table A.9

Fluid-1 (with 9 HC): Relative Deviation (RD) in calculated Upper Onset Pressure (UOP) with respect to experimental data for different amount of gas injections and considering different asphaltene molecular weight.

\begin{tabular}{|c|c|c|c|c|c|c|c|c|c|c|c|c|c|c|c|c|c|c|c|c|}
\hline \multirow{3}{*}{$\begin{array}{l}\text { Asp } \\
\text { MW } \\
\text { (Da) }\end{array}$} & \multicolumn{5}{|c|}{$\mathrm{H} / \mathrm{C}$ Gas Injection $=0 \mathrm{~mol} \%$} & \multicolumn{5}{|c|}{$\mathrm{H} / \mathrm{C}$ Gas Injection=5 mol\% } & \multicolumn{5}{|c|}{$\mathrm{H} / \mathrm{C}$ Gas Injection=15 $\mathrm{mol} \%$} & \multicolumn{5}{|c|}{$H / C$ Gas Injection=30 mol\% } \\
\hline & \multirow{2}{*}{$\begin{array}{l}\text { Exp } \\
\text { Temp } \\
\text { (K) }\end{array}$} & \multirow{2}{*}{$\begin{array}{l}\text { Exp } \\
\text { UOP } \\
\text { (bar) }\end{array}$} & \multicolumn{3}{|c|}{$\begin{array}{c}\text { RD in calculated } \\
\text { UOP } \\
(\%)\end{array}$} & \multirow{2}{*}{$\begin{array}{l}\operatorname{Exp} \\
\text { UOP } \\
\text { (bar) }\end{array}$} & \multirow{2}{*}{$\begin{array}{l}\text { Exp } \\
\text { UOP } \\
\text { (bar) }\end{array}$} & \multicolumn{3}{|c|}{$\begin{array}{c}\text { RD in calculated } \\
\text { UOP } \\
(\%)\end{array}$} & \multirow{2}{*}{$\begin{array}{l}\text { Exp } \\
\text { Temp } \\
(\mathrm{K})\end{array}$} & \multirow{2}{*}{$\begin{array}{l}\text { Exp } \\
\text { UOP } \\
\text { (bar) }\end{array}$} & \multicolumn{3}{|c|}{$\begin{array}{c}\text { RD in calculated } \\
\text { UOP } \\
(\%)\end{array}$} & \multirow{2}{*}{$\begin{array}{l}\text { Exp } \\
\text { Temp } \\
(\mathrm{K})\end{array}$} & \multirow{2}{*}{$\begin{array}{l}\text { Exp } \\
\text { UOP } \\
\text { (bar) }\end{array}$} & \multicolumn{3}{|c|}{$\begin{array}{c}\text { RD in calculated } \\
\text { UOP } \\
(\%)\end{array}$} \\
\hline & & & CPA & SRK & $\begin{array}{c}\text { SRK } \\
+ \\
\text { HV }\end{array}$ & & & CPA & SRK & $\begin{array}{c}\text { SRK } \\
+ \\
\text { HV }\end{array}$ & & & CPA & SRK & $\begin{array}{c}\text { SRK } \\
+ \\
\text { HV }\end{array}$ & & & CPA & SRK & $\begin{array}{c}\text { SRK } \\
+ \\
\text { HV }\end{array}$ \\
\hline \multirow{4}{*}{6165} & 328 & 107 & -69 & -60 & -59 & 328 & 238 & 0 & 0 & 0 & & & & & & & & & & \\
\hline & 347 & 126 & -15 & -13 & -10 & 347 & 193 & 0 & 0 & 0 & 347 & 296 & -6 & -11 & -11 & 347 & 630 & 7 & -3 & -1 \\
\hline & 394 & 152 & 2 & 2 & 2 & 394 & 168 & 0 & 0 & 3 & 394 & 257 & 0 & 2 & 3 & 394 & 481 & 7 & 12 & 11 \\
\hline & & AAD & 29 & 25 & 24 & & & 0 & 0 & 1 & & & 3 & 6 & 7 & & & 7 & 7 & 6 \\
\hline
\end{tabular}

